OPEN ACCESS

Edited by:

Francesco Peri,

University of Milano-Bicocca, Italy

Reviewed by:

Jerrold Weiss,

The University of lowa, United States

Edward Sherwood,

Vanderbilt University Medical Center,

United States

*Correspondence:

Alla Zamyatina

alla.zamyatina@boku.ac.at

Specialty section:

This article was submitted to

Molecular Innate Immunity,

a section of the journal

Frontiers in Immunology

Received: 19 July 2020

Accepted: 23 October 2020

Published: 27 November 2020

Citation:

Zamyatina A and Heine H (2020) Lipopolysaccharide Recognition in the Crossroads of TLR4 and Caspase-4/ 11 Mediated Inflammatory Pathways.

Front. Immunol. 11:585146

doi: 10.3389/fimmu.2020.585146

\section{Lipopolysaccharide Recognition in the Crossroads of TLR4 and Caspase-4/11 Mediated Inflammatory Pathways}

\author{
Alla Zamyatina ${ }^{1 *}$ and Holger Heine ${ }^{2}$ \\ 1 Institute of Organic Chemistry, Department of Chemistry, University of Natural Resources and Life Sciences, Vienna, \\ Austria, ${ }^{2}$ Research Group Innate Immunity, Research Center Borstel-Leibniz Lung Center, Airway Research Center North \\ (ARCN), German Center for Lung Disease (DZL), Borstel, Germany
}

The innate immune response to lipopolysaccharide is essential for host defense against Gram-negative bacteria. In response to bacterial infection, the TLR4/MD-2 complex that is expressed on the surface of macrophages, monocytes, dendritic, and epithelial cells senses picomolar concentrations of endotoxic LPS and triggers the production of various pro-inflammatory mediators. In addition, LPS from extracellular bacteria which is either endocytosed or transfected into the cytosol of host cells or cytosolic LPS produced by intracellular bacteria is recognized by cytosolic proteases caspase-4/11 and hosts guanylate binding proteins that are involved in the assembly and activation of the NLRP3 inflammasome. All these events result in the initiation of pro-inflammatory signaling cascades directed at bacterial eradication. However, TLR4-mediated signaling and caspase-4/11-induced pyroptosis are largely involved in the pathogenesis of chronic and acute inflammation. Both extra- and intracellular LPS receptors-TLR4/MD-2 complex and caspase-4/11, respectively-are able to directly bind the lipid A motif of LPS. Whereas the structural basis of lipid A recognition by the TLR4 complex is profoundly studied and well understood, the atomic mechanism of LPS/lipid A interaction with caspase-4/11 is largely unknown. Here we describe the LPS-induced TLR4 and caspase4/11 mediated signaling pathways and their cross-talk and scrutinize specific structural features of the lipid A motif of diverse LPS variants that have been reported to activate caspase-4/11 or to induce caspase-4/11 mediated activation of NLRP3 inflammasome (either upon transfection of LPS in vitro or upon infection of cell cultures with intracellular bacteria or by LPS as a component of the outer membrane vesicles). Generally, inflammatory caspases show rather similar structural requirements as the TLR4/MD-2 complex, so that a "basic" hexaacylated bisphosphorylated lipid A architecture is sufficient for activation. However, caspase-4/11 can sense and respond to much broader variety of lipid A variants compared to the very "narrow" specificity of TLR4/MD-2 complex as far as the number and the length of lipid chains attached at the diglucosamine backbone of lipid 
A is concerned. Besides, modification of the lipid A phosphate groups with positively charged appendages such as phosphoethanolamine or aminoarabinose could be essential for the interaction of lipid A/LPS with inflammatory caspases and related proteins.

Keywords: lipid A, inflammation, chemical structure, innate immunity, structural basis, molecular recognition, TLR4/MD-2, aminoarabinose

\section{LIPOPOLYSACCHARIDE DETECTION BY THE INNATE IMMUNE SYSTEM}

Early detection of pathogen-associated molecular patterns (PAMPs) universally shared by Gram-negative bacteria is a crucial element for the initiation of innate immune responses such as inflammation $(1,2)$. LPS is a glycan based Gram-negative PAMP that is either expressed on the bacterial cell surface or associated with intracellular or outer membrane vesicles (OMV). LPS prompts the induction of mammalian innate immune responses through a meticulously organized sequential event that starts with the binding of LPS to LPS-binding protein (LBP), transfer to cluster of differentiation-14 (CD14) and, finally, engagement of the germline-encoded patternrecognition receptor (PRR) Toll-like receptor 4/myeloid differentiation-2 (MD-2) complex (3-6). TLR4 is a type I transmembrane protein entailing a leucine-rich repeats ectodomain, a transmembrane domain and a cytosolic Toll-IL-1 receptor (TIR) domain which is involved in induction of the downstream signaling cascades. MD-2 is a secreted accessory molecule which is physically associated with TLR4 and essential for LPS recognition and binding. LPS-induced homodimerization of ternary TLR4/MD-2/LPS complexes results in the assembly of particular intracellular adaptor protein complexes which leads to the activation of various transcription factors such as NF- $\mathrm{KB}$, followed by induction of expression of cytokines and IFNs. Inadequate regulation of the TLR4 signaling contributes to the pathogenesis of a number of acute and chronic inflammatory as well as autoimmune diseases such as allergy, arthritis (7-9), asthma (10-12), cardiovascular disorders (13), Alzheimer disease-associated pathology (14) and systemic inflammatory response syndrome (SIRS) and septic shock $(15,16)$. Impressive research demonstrated that down-regulation of the TLR4 mediated signaling can be useful for therapeutic benefits and efficient for management of asthma (17, 18), arthritis, (8) viral infections [influenza (19) and Ebola virus (20)], cancer (21), and sepsis (22). Besides, TLR4-mediated signaling has been demonstrated to promote dendritic cells maturation thereby linking innate and adaptive immunity $(23,24)$ which features activation of the TLR4/MD-2 complex by TLR4-specific ligands of low toxicity as facile approach for development of novel vaccine adjuvants (25-27).

Whereas detection of extracellular LPS and ensuing immune responses through TLR4 signaling pathway plays a major role in the primary detection of LPS, the recognition of cytosolic LPS by intracellular proteases caspase-4/5 (and their mouse homologue caspase-11) is important at a later stage of severe bacterial infection (28-31). Inflammatory caspases are parts of the noncanonical inflammasome pathway involved in the initiation of a series of inflammatory effects such as endocytosis, autophagy and oxidative burst $(28,32,33)$. Activated caspase- $4 / 5 / 11$ induces NLRP3 inflammasome activation and triggers the secretion of IL-1 $\beta$ and IL-18 via caspase- 1 mediated processing of pro-IL-1 $\beta$ and pro-IL-18, and pyroptosis accounting for endotoxin-related pathology (34-36). Recent studies have underscored the significance of the non-canonical inflammasome signaling in acute and chronic inflammatory conditions including sepsis (3739), diabetes (40), atherosclerosis (41), and Alzheimer's disease $(42,43)$. Although human caspase- 5 has been shown to function similar to caspase-4, it is less studies in respect to LPS recognition. In this review we make emphasis on caspase-4/11 and mention caspase- 5 whenever appropriate.

\section{TLR4-Mediated Signaling Pathways}

Upon engagement of MD-2 and TLR4 and the LPS-mediated generation of TLR4/MD-2/LPS homodimers, intracellular signaling is initiated by conformational changes of the Toll/IL-1R (TIR) domain of TLR4. Among all TLRs, TLR4 is unique since it is the only TLR that uses both major signaling adaptors, MyD88 (myeloid differentiation primary response 88) (44) and TIR (Toll IL-1R) -domain containing adaptor inducing Interferon- $\beta$ [TRIF (45)], as well as the respective adaptor molecules MyD88-adaptorlike [MAL (46)], which is also known as TIR-domain containing adaptor protein [TIRAP (47)] and TRIF-related adaptor molecule [TRAM (48)]. This uniqueness enables TLR4 to induce two different sets of responses: the first set starts at the plasma membrane, depends on MyD88 and leads to a rapid induction of pro-inflammatory cytokines (Figure 1). The second set requires internalization, depends on TRIF and emanates signals from endosomal membranes which lead to the induction of a type I interferon response.

MyD88 is a 296 aa adaptor protein containing two major domains: a C-terminal TIR domain which associates with other TIR domain-containing proteins and a $\mathrm{N}$-terminal death domain (DD) which mediates the interaction with the IRAK (IL-1Rassociated kinase) family kinases (49-51). Whereas recruitment to TLR4 is facilitated by homotypic TIR domain interactions and requires the bridging adaptor $\operatorname{MAL}(52,53)$, DDs are used to engage members of the IRAK family to the complex. The whole complex comprises of 14-16 MyD88 and IRAK1, -2, and -4 molecules and has been termed the myddosome (54). Such multi-molecular complexes that are functioning as signaling platforms have been termed supramolecular organizing centers (SMOCs) and are crucially important for innate immune 


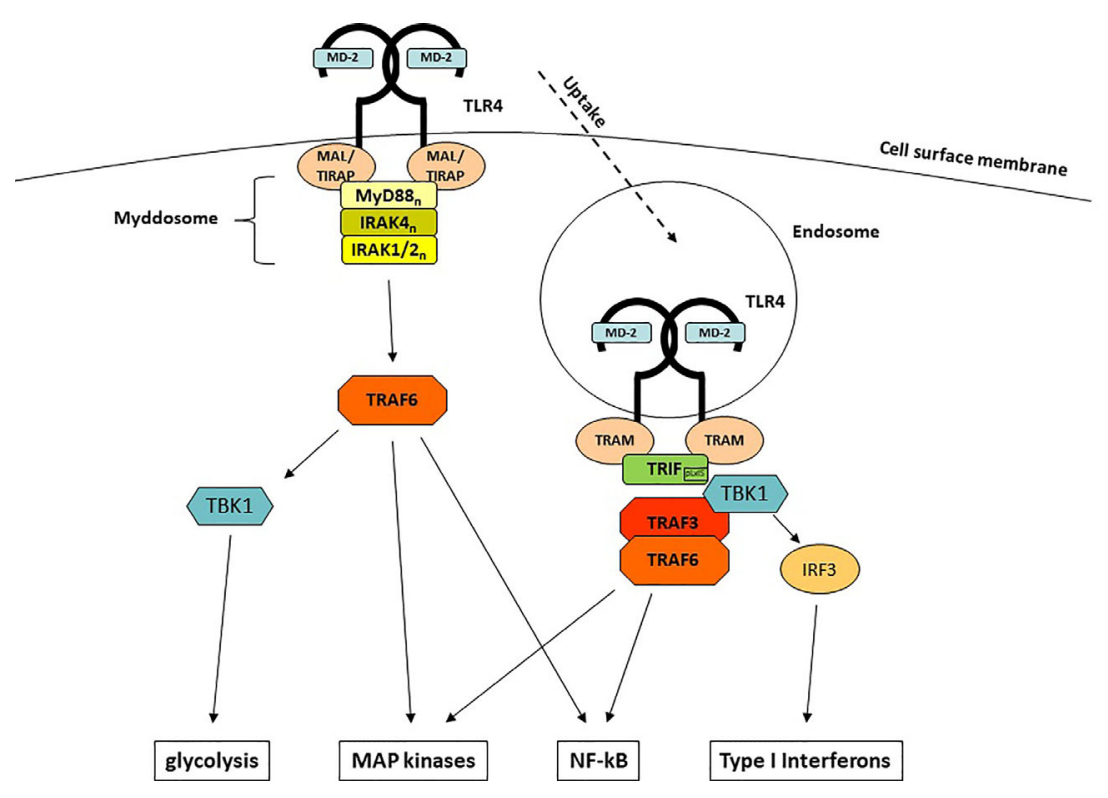

FIGURE 1 | LPS-induced TLR4-mediated signaling pathways.

signaling (55). The myddosome formation leads to autophosphorylation of the kinase domain (KD) of IRAK4 (56, 57), which in turn activates IRAK1/2. Subsequently, another central (but not exclusive) element of LPS-induced signaling, the E3 ubiquitin ligase TNF receptor-associated factor 6 (TRAF6) $(58,59)$ associates and gets activated. TRAF6 is central to immune activation (60), as it is able to induce further downstream major signaling pathways that end up in the activation of crucial innate immune transcription factors through TAK1 (NF- $\mathrm{BB}$ and AP-1) $(61,62)$ as well as the induction of glycolysis through TBK1 $(63,64)$.

Early investigations of MyD88-deficient animals and cells showed that not all LPS responses were completely abolished but rather delayed (44). The reason for the delayed response is the site of its origin: whereas the MyD88-dependent responses are initiated at the cell membrane, the MyD88-independent responses emanate from TLR4-harboring endosomes once MyD88 is discharged from TLR4 (65). The molecule responsible for this surprising effect is $\operatorname{TRIF}(45,66)$. In contrast to TLR3 which can directly recruit TRIF, TLR4 needs assistance from the adaptor protein $\operatorname{TRAM}(48,66)$. Upon binding of TRAM/TRIF to endosomal TLR4, the E3 Ub ligase TRAF3 (67) is recruited and subsequently activates TBK1. Although TBK1 is also part of the MyD88/TRAF6-dependent signaling, it only leads in conjunction with TRIF to the induction of IFNs, the hallmark of the TRIF-dependent immune response: a so-called pLxIS motif in TRIF becomes phosphorylated by TBK1 and can interact with the key interferon-regulatory factor IRF-3 (68), which by itself is another substrate for TBK1 $(69,70)$. In addition to TRAF3, TRIF can also recruit TRAF6, which explains the delayed NF- $\mathrm{KB}$ translocation and MAP kinase activation seen in MyD88-deficient cells.
Most of the LPS-induced cytokines, chemokines and interferons are regulated through the induction of mRNA expression. However, one of the major pro-inflammatory cytokine, IL-1 $\beta$ (as well as its related IL-1-superfamily member IL-18) which regulates a wide array of immune and physiological responses (71), requires an additional step of maturation/ processing by caspase-1 (72). The multi-protein complexes facilitating this maturation are another example of SMOCs (s. above) and have been termed inflammasomes (73). The most important inflammasome responsible for TLR4-dependent IL-1 $\beta$ release consists of the processing protease caspase-1, the adaptor protein ASC and the NLR protein $\operatorname{NLRP3}(74,75)$. The overall production of IL- $1 \beta$ induced by LPS is controlled on several different levels: induction of NLRP3 and IL-1 $\beta$ mRNA (in part through translocation of NF- $\mathrm{KB})(76,77)$, phosphorylation and ubiquitination of NLRP3 on multiple sites (78-81). Eventually, IL- $1 \beta$ is released by the cells through a process called pyroptosis culminating in Gasdermin D-forming pores in the cell membrane (see also 1.2) (82-84). There are multiple pathways to activate inflammasomes, termed canonical and non-canonical inflammasome activation [reviewed in (85)] and interestingly, LPS shows another species-specific peculiarity: in human cells, LPS is able to induce IL- $1 \beta$ release through an additional inflammasome activating pathway, called alternative activation, which does not require potassium efflux and pyroptosis but uses the TLR4-TRIF axis to activate NLRP3 through caspase 8 (86).

\section{Caspase-4/11 Mediated Signaling Pathways}

Since its discovery in 1999, TLR4 was long believed to be the sole LPS receptor. So it was a surprising finding, when the first reports came out in 2013 showing that intracellular cytosolic 
LPS - independent of TLR4 - was able to trigger noncanonical caspase-11-dependent inflammasome activation that was accompanied by IL-1 $\beta$ release and pyroptosis $(28,34)$. Subsequently, it was revealed that it is actually caspase-11 and its human orthologs, caspases 4 and 5, that directly bind and get activated by LPS $(30,31,87)$.

Binding of LPS by these caspases is mediated by their CARD domain and leads to oligomerization and proximity-induced activation $(30,88)$. Within this process, auto-proteolysis at Asp285 in the inter-subunit linker of caspase-11 is also required (87). The molecular mechanism by which pyroptosis as well as the release of IL-1 $\beta$ and IL-18 is facilitated was unidentified for many years, despite enormous efforts from multiple groups. Then, in 2015, the long-sought-after molecule was identified as Gasdermin D $(82,89)$. Gasdermin D belongs to a family of 6 members (based on sequence homology), all harboring an auto-inhibitory carboxy-terminal domain (CTD) linked to the membrane pore-forming amino-terminal domain (NTD). Proteolytically active caspase-11 then cleaves Gasdermin $\mathrm{D}$ within the linker region, effectively separating the two domains from each other. Since the NTD has a high affinity to the negatively charged membrane phospholipids such as phosphoinositides and cardiolipin, it localizes to the plasma membrane. Finally, the NTD self-assembles to form pores presumably out of 26-28 NTDs in the plasma membrane which rapidly induce pyroptosis and allow the release of IL- $1 \beta$ and IL-18 (82, 83, 89-94). Caspase-11 activation induced by intracellular LPS also drives the release of pro-inflammatory cytokines, interleukin (IL)-1 $\beta$ and IL-18 by triggering the activation of the NLRP3 inflammasome. But how is the activation of the NLRP3 inflammasome achieved? Neither caspase-11 nor Gasdermin D do activate the NLRP3 inflammasome directly, but it has been shown that Gasdermin $\mathrm{D}$ expression is absolutely required for the activation (89). Due to the size of the NTD pores, they are also non-selective ion channels and thus, enable the efflux of potassium which in itself is known driver of NLRP3 inflammasome activation (95).

\section{Crosstalk of TLR4- and Caspase 4/11- Dependent Signaling Pathways}

The TLR4- as well as the caspase 4/5/11-dependent signaling events induced by LPS are not independent from each other but rather cross-interact at different levels. For example, the expression of caspase-11 is very low under normal conditions, but significantly induced by LPS, whereas the expression of caspase- 4 is relatively constant, even in the absence of a priming signal (30). How does LPS induce transcriptional expression of caspase-11? In 2012, the data that TRIFdependent signaling is licensing caspase-11 for NLRP3 inflammasome activation were convincingly presented $(33,96)$. This licensing is not mediated by direct interaction of TRIF and caspase-11, but requires Type IFNs. As explained in earlier, TRIF initiates activation of IRF3/7 and the induction of Type I interferon release. The released Type I IFNs then activate in an autocrine/paracrine manner the cell via IFNAR1/2-dependent JAK/STAT signaling to initiate pro-caspase-11 expression. In addition, Type I IFNs also drive the expression of GBPs and IRGB10 that are required for caspase-11-dependent responses towards LPS (97-99). Another molecule involved in both the extracellular/endosomal and the cytosolic LPS response is caspase- 8 . Caspase- 8 belongs to the pro-apoptotic caspases and takes part of the alternative inflammasome activation by LPS in human cells (86). However, caspase- 8 also cooperates with caspase-11 in the tissues to execute the final steps of endotoxic shock, i.e., tissue injury and cell death (100). The activation of both caspases is cytokine driven, caspase- 8 by TNF and caspase11 , as already mentioned, by Type I IFNs, implicating both the LPS/TLR4/MyD88-dependent pathway (TNF) and the LPS/ TLR4/TRIF-dependent pathway (TRIF) in this process.

\section{RECOGNITION OF LIPID A/LPS BY THE TLR4/MD-2 COMPLEX}

\section{Structural Determinants of Lipid A/LPS Guiding Activation of the TLR4/MD-2 Complex in Relation to Virulence}

LPS is a micro-heterogeneous bacterial glycan which is constituted of three major motifs: the membrane-anchored lipid $\mathrm{A}$, the conserved core oligosaccharide and the variable $\mathrm{O}$ antigen, whereas the lipid A portion exemplifies an "endotoxic principle" of LPS (101-104). Glycolipid "lipid A"-a small ( 2 $\mathrm{kDa}$ ) amphiphilic terminal fragment of LPS-is responsible for the activation of the host innate immune response through engagement of two major LPS sensing platforms: transmembrane TLR4/MD-2 complex $(105,106)$ and cytosolic inflammatory caspases (30). Structurally, lipid A is composed of a polar "head group" and a bulky hydrophobic cluster entailing four to seven long chain 3-hydroxylated lipid residues $(107,108)$. The polar region of lipid A consists of a $\beta(1 \rightarrow 6)$-linked diglucosamine backbone which is decorated by two phosphate groups - at position $4^{\prime}\left(\mathrm{P}-4^{\prime}\right)$ of a distal GlcN residue and at position 1 (P-1) of a proximal GlcN moiety (Figure 2). Positions 2,3 and $2^{\prime}, 3^{\prime}$ of the proximal and the distal glucosamines are usually acylated by the long chain $(R)$-3-hydroxyalkanoic and/or (R)-3-acyloxyalkanoic acids. The endotoxic activity of LPS generally relies on the number, length and distribution of lipid chains along the disaccharide backbone of lipid A as well as on the phosphorylation status of the sugar units. A canonical endotoxic lipid A of E. coli is hexa-acylated (the lipid chains entail 12 to 14 carbon atoms) and possesses two phosphate groups. The non-endotoxic lipid $\mathrm{A}$ variants are usually underacylated, and/or possess longer $\left(\mathrm{C}_{16}-\mathrm{C}_{18}\right)$ lipid chains and lack at least one of the phosphate groups. The TLR4/MD-2 receptor complex responds to very low concentrations (picomolar magnitudes) of LPS via recognition and binding of distinct structural motifs of lipid A through majorly hydrophobic, but also ionic interactions.

The lipid A binding site on MD-2 is remarkably large and consists of a deep hydrophobic Leu- and Phe- rich cavity, crowned on the top with a number of Arg and Lys residues. Hydrophobic groove of MD-2 can accommodate multiple 


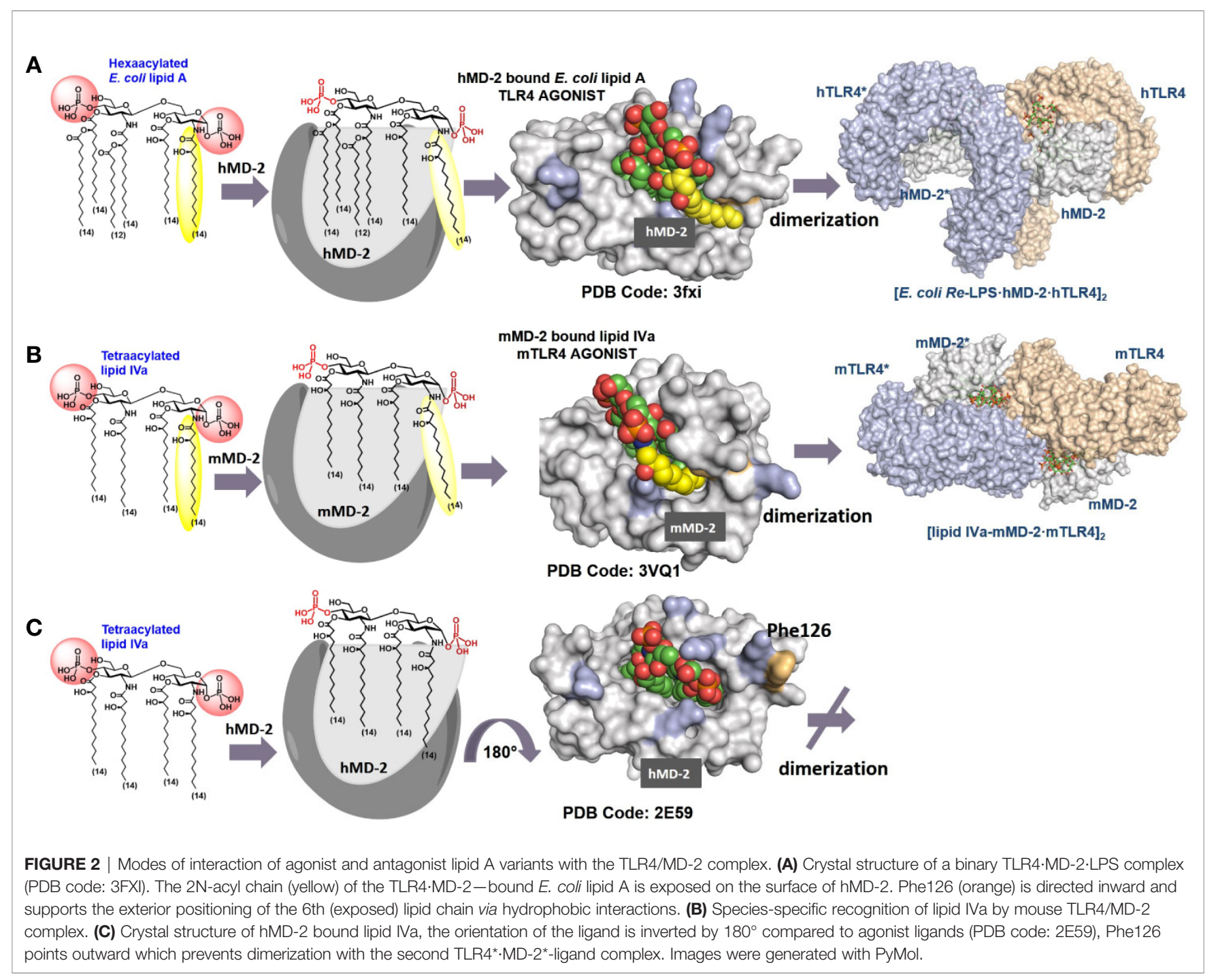

acyloxy- and acyloxyacyl lipid chains, whereas positively charged side chains at the rim of the binding pocket can establish ionic interactions with the lipid A phosphate groups (5). MD-2 is physically associated with TLR4 and the contact area is designated "primary dimerization interface". Binding of the lipid A motif of LPS by MD-2 initiates and supports the assembly of a hexameric ligand-receptor complex constituted of two copies of the TLR4/MD-2/LPS homodimer (Figure 2A). LPS-induced TLR4 complex dimerization is facilitated by hydrophobic interactions of a specific lipid chain of the MD2-bound lipid A with the second TLR4* (designated as "secondary dimerization interface") (6). Upon formation of a [TLR4/MD-2/LPS] ${ }_{2}$ complex, the intracellular TIR domains come into vicinity which triggers the recruitment of a number of adaptor proteins (109). The latter event eventually leads to the assembly of a large macromolecular signaling complex called "Myddosome" that, in turn, triggers diverse pro-inflammatory signaling pathways $(110,111)$.

Generally, binding of the bisphosphorylated hexaacylated lipid A from E. coli-a typical TLR4 agonist - results in the efficient TLR4 complex dimerization and robust activation of the pro-inflammatory signaling, whereas binding of tetraacylated lipid A variants blocks the binding pocket of MD-2 for the interaction with endotoxic LPS, thus rendering these lipid A types to potent TLR4 antagonists (Figure 2C) $(112,113)$. The principal differences in binding modes of agonist and antagonist lipid $\mathrm{A}$ include 1 ) the number of lipid chains (four to five) accommodated in the binding pocket of MD-2;2) the orientation (binding pose $+/-180^{\circ}$ ) of the carbohydrate backbone of lipid A within the binding pocket of the co-receptor MD-2;3) the deepness of insertion of the lipid A molecule into the binding cleft of MD-2 (TLR4 antagonists are accommodated deeper in the binding grove of MD-2 compared to agonist lipid A variants); and 4) ligand-induced rearrangement of MD-2 discriminated by different positioning Phe126 residue (located inward for agonist lipid A and outward for antagonist lipid A).

Accordingly, all four long-chain acyloxy residues of underacylated lipid A variants are entirely intercalated into the hydrophobic binding pocket of human MD-2, the lipid A molecule adopts "inverted" orientation with phosphate group 
$\mathrm{P}-4^{\prime}$ facing secondary dimerization interface, and the whole molecule is inserted deeper into the binding pocket compared to agonist lipid A (Figure 2C) (112, 113). A number of natural and synthetic antagonist lipid As and analogues were shown to selectively bind to MD-2/TLR4 without triggering receptor complex dimerization (112-114). These compounds are extensively studied as candidates for potential therapeutic inhibition of harmful endotoxic effects induced by TLR4 activation (115-117).

In contrast, TLR4 activating lipid A variants are housed in the binding pocket of MD-2 with the glycosidic phosphate P-1 bordering secondary dimerization interface. Thus, the lipid A molecule is rotated by $180^{\circ}$ in the binding pocket of MD-2 compared to antagonist binding mode (Figures 2A, B). The binding pocket of MD-2 can accommodate only five lipid chains of hexaacylated $E$. coli lipid A, while the $6^{\text {th }} 2 N$-acyl lipid chain (linked to the proximal GlcN residue of the diglucosamine backbone) is excluded from the binding grove and presented on the surface of MD-2 at the site engaged in the dimerization with the second TLR4* (secondary dimerization interface). The expulsion of lipid chain out of the binding pocket and the resulting reorganization of the secondary structure of MD-2 is considered the major driving force of the dimerization process $(5,6)$. It is now well established that both ionic interactions of the lipid A phosphate groups with the Lys and Arg side chains as well as intermolecular hydrophobic interaction of the exposed $2 \mathrm{~N}$ acyl chain with the second TLR $4^{\star}$ contribute to receptor complex dimerization and formation of the active [TLR4/MD-2/LPS $]_{2}$ hexamer (118-120).

The positioning of the ligand $\left(+/-180^{\circ}\right)$ within the binding cleft of MD-2 appears to be crucial for the expression of a particular biological activity. Thus, tetraacylated lipid IVa acts as antagonist at hTLR4 but performs as weak agonist at mouse (m-) TLR4 wherein it binds in an inverted by $180^{\circ}$ orientation (similar to $E$. coli lipid A in the binding pocket of hMD-2) and exposes one lipid chain on the surface of the protein (Figure 2B) $(6,121)$. Speciesspecificity in ligand recognition by the TLR4 system, which is decisive for transition of in vivo data obtained in rodent or other animal models to clinical trials, is still not well understood. In addition to the length and number of lipid chains, the distribution pattern of acyl residues along the glucosamine backbone is decisive for lipid A recognition by the TLR4/MD-2. For instance, lipid A variants having four lipid chains attached at the distal GlcN ring and two lipid chains linked to the proximal GlcN $(4+2$ acylation pattern as in E. coli) as well as lipid A variants with the acylation pattern $(3+3)$ as in $N$. meningitidis are the most powerful TLR4 activators; penta-acylated lipid As with $(3+2)$ acylation pattern are inactive (or weakly active), whereas penta-acyl lipid A having $(4+1)$ acylation pattern retains robust activating potential similar to $E$. coli lipid A $(122,123)$.

\section{LPS Is Delivered to the TLR4/MD-2 Complex by the Proteins of the LPS Transfer Cascade}

LPS is an amphiphilic molecule that contains a relatively small hydrophobic lipid region retaining LPS in the lipid (bi)layer (in the outer leaflet of the outer bacterial membrane or in the lipid layer of the endosomes/OMVs) and a large hydrophilic carbohydrate portion (inner and outer core, O-antigen) which is decorated by a number of negatively and positively charged appendages such as phosphates, phosphoethanolamines, or amino sugars. Despite its large size and complexity, LPS is recognized by the innate immune system through a fine-tuned molecular mechanism which is extraordinary sensitive to minor variations in the structure of lipid A. Regardless its relative heterogeneity in respect to acylation pattern, lipid A represents the most conserved fragment of LPS. Lipid A has an ability to establish high affinity interactions with a number of proteins involved in the LPS transfer and recognition cascades. Prior to interaction with TLR4, the LPS molecule must be "extracted" from the membrane surfaces and transferred to the binding pocket of MD-2 $(124,125)$ which requires a successive interaction of LPS with LPB (3), and the GPI-anchored differentiation antigen of monocytes $\operatorname{CD} 14(4,126,127)$. LBP binds sequentially to LPS micelles and to CD14 to form a dynamic intermediate LBP/LPS/CD14-complex, and accomplishes multiple rounds of LPS transfer to CD14. In turn, CD14/LPS rapidly dissociates from LPB-LPS complex and transfers a single LPS molecule to MD-2/TLR4 via a direct physical interaction between LRR13-LRR15 domains of TLR4 with CD14/LPS (4). In addition, CD14 mediates LPS internalization through LPS-induced endocytosis of TLR4/MD2/LPS complexes which eventually leads to endosome-mediated TRIF-dependent signaling resulting in interferon production as well as in activation of NF- $\kappa \mathrm{B}(128,129)$. Although the crystal structures of LBP and CD14 are available (130-132), and the fine dynamics of the LPS transfer cascade by LBP and CD14 has been recently deciphered (4), the precise atomic mechanism and structural background of the LPS/lipid A recognition by LBP and CD14 are still not fully understood. Whereas LPS binding by LBP involves positively charged patches at the LBP N-terminal domain which could attract the phosphate groups/negative charges of LPS by ionic forces (131), CD14 possesses several hydrophobic cavities surrounded by positively charged sidechains which, most likely, bind LPS through majorly hydrophobic but also ionic interactions (132).

\section{INTERACTION OF LIPID A/LPS WITH INFLAMMATORY CASPASES}

In addition to the activation of a canonical (caspase-1-dependent) inflammasome, LPS mediates the noncanonical (caspase-4/11 dependent) inflammasome activation when mammalian immune cells are challenged with intracellular bacteria including Shigella flexneri, Salmonella enterica serovar Typhimurium ( $S$. typhimurium), Legionella pneumophila, Francisella novicida, several Burkholderia species, and Chlamydia trachomatis as well as extracellular bacteria such as enterohemorrhagic E. coli (EHEC), Citrobacter rodentium, and Yersinia pseudotuberculosis. For noncanonical inflammasome activation, the bacterial products such as LPS must be translocated into the host cytosol which can be achieved 
via type III (T3SS) or type IV secretion system (T4SS) abundantly expressed in the infectious strains of several bacteria $(31,133)$.

\section{Cytosolic Delivery of LPS for Noncanonical Inflammasome Activation}

LPS is a relatively large $20 \mathrm{kDa}$ glycan which cannot cross cellular membranes by itself, so that sophisticated molecular mechanisms are required to deliver or transfect LPS derived from non- cytosolic bacteria into the cytosol of the hosts' immune cells for non-canonical inflammasome activation. Also, many intracellular bacteria survive within vacuoles and use special protein complexes to let their PAMPs access the host cytosol. It has been proposed that LPS can enter the cytosol through multiple pathways.

Intracellular bacteria which reside and replicate within distinct cellular compartments evolved special secretion systems to allow LPS to access cytosol. For example, Salmonella uses type 3 secretion system (T3SS) to invade epithelial cells and to establish vacuolar compartments (SCV, Salmonella-containing vacuole), which helps bacteria to survive within phagocytes (133). LPS can gain access to the cytosol through lysis of bacteriacontaining vacuoles formed by eukaryotic membranes of the host cells $(134,135)$. Also L. pneumophila usually survives within the vacuole, although certain mutants can atypically enter the cytosol (135). Since many Gram-negative pathogens known to activate caspase-4/11 are not cytosolic, a specific molecular mashinery which allows LPS from these bacteria to gain access to the cytosol for caspase-4/11 activation has been evolved.

One of the plausible mechanisms for LPS internalization and intracellular delivery involves LPS binding by high-mobility group box 1 (HMGB1) - an alarmin which can efficiently transport LPS into the cytoplasm through receptor for advanced glycation end products (RAGE)-mediated endocytosis $(17,136,137)$. Through internalization of HMGB1-LPS complexes mediated by RAGE, HMGB1 induces destabilization of lysosomes for cytosolic LPS delivery. HMGB1 was demonstrated to bind LPS via LPS-binding domains (the $\mathrm{A}$ and $\mathrm{B}$ box), although the structural requirements for LPS recognition by HMGB1 are currently unknown (138). TLR4 activation by LPS was shown to induce HMGB1 release from hepatocytes followed by direct LPS binding, and the LPS translocation by induction of lysosomal rupture. Interestingly, HMGB1 has long been supposed to have high affinity to LPS and to interfere with TLR4/MD-2/CD14 signaling $(138,139)$. Another report describes elevated production of HMGB1 in hepatocytes in response to the LPS-induced TLR4 and caspase$11 /$ Gasdermin D signaling (140) indicating that HMGB1 represents a danger molecule released in response to NLRP3 inflammasome activation.

It has been also suggested that outer membrane vesicles (OMVs) - the naturally secreted products of Gram-negative bacteria-can function as cytosolic LPS delivery vehicles (141). Generally, OMVs promote the induction of pro-inflammatory mediators in vivo during infection with Gram-negative pathogens such as $H$. pylori, L. pneumophila, S. typhimurium and other (142). The membrane composition of OMVs is rich with LPS required for OMV stability and is very similar to the content of extracellular vesicles formed by eukaryotic cells (143). Recent studies suggest that OMVs can directly transport membrane-associated PAMPs into the host cells where they can be taken up through endocytosis, or act as vehicle for the internalization of LPS into the cytosol (144-147). Furthermore, internalization of LPS-containing OMVs by guanylate-binding proteins (GBPs, interferon-inducible GTPases) promotes localization of LPS in the cytoplasm followed by caspase-4/11 mediated activation of NLRP3 $(134,148)$. GBPs associate with LPS-containing membrane surfaces and contribute to cytosolic immune detection of LPS by facilitating its interaction with caspase-4/11. GBPs were also shown to assist in disruption of pathogen-containing vacuoles thus allowing LPS of cytosolic bacteria to reach the cytosol $(97,149)$.

\section{Guanylate-Binding Proteins as Co-Factors for Caspase-4/11 Mediated LPS Sensing}

Caspase-4/11 was shown to directly bind to the lipid A motif of LPS, however, lipid A is hidden in the bacterial outer membrane or embedded within the lipid bilayer of liposomal aggregates spontaneously formed by LPS. Therefore, a central question on how the membrane-anchored LPS can interact by its lipid A motif with the CARD of the cytosolic protein caspase-4/11 had to be answered. Recently, guanylate-binding proteins (GBPs) were suggested to govern the recruitment of caspase-4/11 to LPS-rich membrane surfaces.

GBPs play a crucial role in antibacterial defense through modulation of both cell-autonomous and innate immunity against Gram-negative bacteria (148). The infection of mouse BMDMs with Gram-negative bacteria induces production of typeI IFNs which consequently upregulates mGBPs $(134,150)$. Activation of GBPs also contributes to secretion of IL-1 $\beta$ and IL-18, and the induction of pyroptosis through activation of the NLRP3 inflammasome and initiation of molecular mechanisms facilitating LPS release into the cytosol of host cells. GBPs were proposed to aid in the LPS uptake from membrane interfaces und thus, to be involved in the activation of caspase-11 and the assembly of noncanonical inflammasome (150).

Different roles and functions were suggested to explain GBPs involvement in the induction of proteolytic activity of caspase-4/ 11. For instance, in the gut infected with S. Typhimurium, GBPs are supposed to contribute to the death and expulsion of infected enterocytes into the lumen. It has been proposed that GBP2dependent liberation of S. typhimurium LPS into the host cytosol through targeting S. typhimurium PCV and promoting its membrane lysis drives caspase-11- and NLRP3-dependent pyroptosis (134). Apparently, GBP2 contributes to induction of caspase- $4 / 11$ proteolytic activity and noncanonical inflammasome activation in response to infection with $F$. novicida (151), $L$. pneumophila (150) and other cytosolic bacteria (99). GBPs have also been shown to be recruited to cytosolic S. flexneri and to prevent spreading of intercellular bacteria by restricting its actindriven motility (149). Interestingly, GBPs were degraded over time by $S$. flexneri bacterial proteasomes which were in turn activated by secreted bacterial effectors (152). It has been also reported that GBP recruitment to bacteria such as $Y$. pseudotuberculosis or $L$. 
pneumophila or their PCVs is dependent on the bacterial type-3 or -4 secretion system, respectively $(153,154)$.

GBPs were demonstrated to be crucial in mediating caspase11 activation in response to outer membrane vesicles (OMVs) from different Gram-negative bacteria such as E. coli, $S$. typhimurium, S. flexneri or P. aeruginosa $(97,98)$. GPBs were suggested to directly deliver LPS into the host cell cytosol after LPS had been internalized through endocytosis. GBPs could physically associate with cytosolic OMVs upon GBPs isoprenylation, and could govern the activation of caspase-11 and Gasdermin D in vivo. Optionally, OMVs could induce recruitment of GBPs through activation of the TLR4-TRIF pathway. In all circumstances, LPS was sufficient to initiate GBPs recruitment in vitro and GBP deficiency protected against OMV-induced lethal endotoxemia in vivo (98).

Thus, it is by now established that the function of guanylatebinding proteins is closely linked to their ability to interact with LPS; however, what part of LPS is recognized by GBPs was very long uncertain. Several studies reported on smooth LPS-induced GBP recruitment to intracellular bacteria which implied the major role of LPS O-antigen in GBPs sensing and the involvement of majorly ionic interactions in this process. Indeed, it was observed that the co-localization of hGBP1 with $S$. flexneri producing LPS- $R a$ mutants was reduced in relation to that of hGBP1 targeting wild-type bacteria, which insinuated that GBP1 recognizes LPS of S. flexneri by its O-antigen (149). Controversially, hGBP2 was shown to mediate caspase-4 activation in response to transfection with tetra-acylated LPS of $F$. novicida (151) which is known to lack the $\mathrm{O}$-antigen and the core sugars $(155,156)$. This suggests variable sensitivity of different GBPs to particular structural features of LPS and that hGBP2 might contain specific lipid A recognizing motifs. In agreement with the latter observation, it was revealed that caspase-11 activation by transfected lipid A is fully GBP dependent (98) whereas GBPs were only partially required for caspase-11 activation induced by smooth or rough (Re-LPS) type S. minnesota LPS. Thus, not only the O-antigen but the lipid A region of LPS could be involved in recognition by GBPs.

Two recent cutting-edge studies independently postulated that the LPS-induced assembly of a GBP coat on the surface of cytosolic Salmonella (or on the LPS-rich membrane interface upon cytosolic delivery of LPS) is indispensable for caspase-4 activation $(157,158)$. Association of GBP1 with the LPS-rich surface of cytosolic Salmonella follows bacterial escape from the vacuole and initiates the recruitment of GBP2-4 to assemble a GBP-derived signaling platform. The LPS-induced GBP coating of bacterial surface promotes the recruitment of caspase- 4 to the cytosolic face of the GBP coat followed by caspase- 4 activation and pyroptosis. Indeed, caspase- 4 can efficiently bind to purified LPS and lipid A by its CARD domain in vitro but does not bind LPS as a constituent of the bacterial outer membrane in cellular experiments in the absence of GBP. Thus, GBPs could make LPS available for the interaction with caspase- 4 by disturbing the integrity of the outer bacterial membrane and making acyl chains of lipid A accessible to their ligand-binding CARD domain.
Further studies are required to understand the structural basis of GBP interaction with lipid A/LPS at the membrane interfaces. The latest findings, however, indicate that GBP1 can directly bind to the LPS coated surface (e.g. outer leaflet of the outer bacterial membrane) and that this interaction is driven by solely ionic forces, whereas the carbohydrate portion of lipid A and the glycan moiety comprising the inner core region are sufficient for LPS-GBP1 interaction $(157,158)$. All O-antigen and outer core lacking mutants of E. coli LPS ( $R a-, R c$-, $R d$-, $R e$-LPS) could associate with GBP1 and induce GBP1 oligomerization at the LPS-rich membrane interface. Negatively charged groups of the inner core sugars of LPS and the phosphate groups attached at the diglucosamine backbone of lipid A were shown to be crucial in promoting GBP1-LPS interaction (which proceeds presumably through involvement of positively charged surface patch of GBP1) and subsequent activation of the non-canonical inflammasome pathway (158). Remarkably, also LPS from $R$. sphaeroides that acts as caspase- 11 antagonist could associate with GBP1 to form higher molecular weight aggregates, which assumes rather broad specificity of GBP1 in recognizing LPS motifs independently on their caspase-4 activity (158). Thus, GBP1 functions as a part of an upstream GBP1-4 complex and orchestrates the recruitment of GBP2-4 to initiate a formation of a signaling platform that is assembled on the LPS-containing membranes. GBP2 and GBP4 are involved in a subsequent recruitment of caspase-4, whereas GBP3 is thought to control its activity (157).

Two alternative modes for GBP-induced caspase- 4 recruitment to membrane-embedded LPS have been proposed. A high molecular weight complex formed by GBP-LPS could promote the recruitment of caspase- 4 and subsequently transfer LPS onto caspase-4 to trigger its activation. Otherwise, the assembly of GBP-LPS complex on the bacterial surface could disturb the integrity of bacterial outer membrane which would allow an access of caspase- 4 to otherwise hidden acyl chains of membrane-anchored LPS (158).

\section{Structural Features Characteristic to Lipid A of Bacterial Species Inducing Caspase- 4/11 Activation: Is There Any Cross- Specificity With TLR4/MD-2?}

It has been unambiguously shown that cytoplasmic LPS triggers caspase-4/11-dependent cell death in human 293T cells and mouse macrophages, respectively. Also, LPS-induced caspase$4 / 11$ oligomerization was observed on the pore-limit native gel and the oligomerization was induced by the fully acylated (hexato heptaacylated) lipid A fragment of LPS from S. typhimurium, C. rodentium, S. flexneri and E. coli (Figure 3) (30). Notably, all LPS forms (LPS- $R a,-R c,-R d$, and $-R e$ ) and $E$. coli lipid A alone could induce caspase-4/11 oligomerization and efficiently stimulated caspase-4/11 activation. Juxtapose, LPS variants bearing fewer lipid chains (LPS from R. sphaeroides and biosynthetic precursor of $E$. coli lipid A, lipid IVa) although being able to bind to caspase-11 CARD (caspase activation and recruitment domain) with the affinity similar to hexaacylated LPS, failed to induce caspase-4/11 oligomerization and activation in vitro. This was consistent with the reports on the inability of 


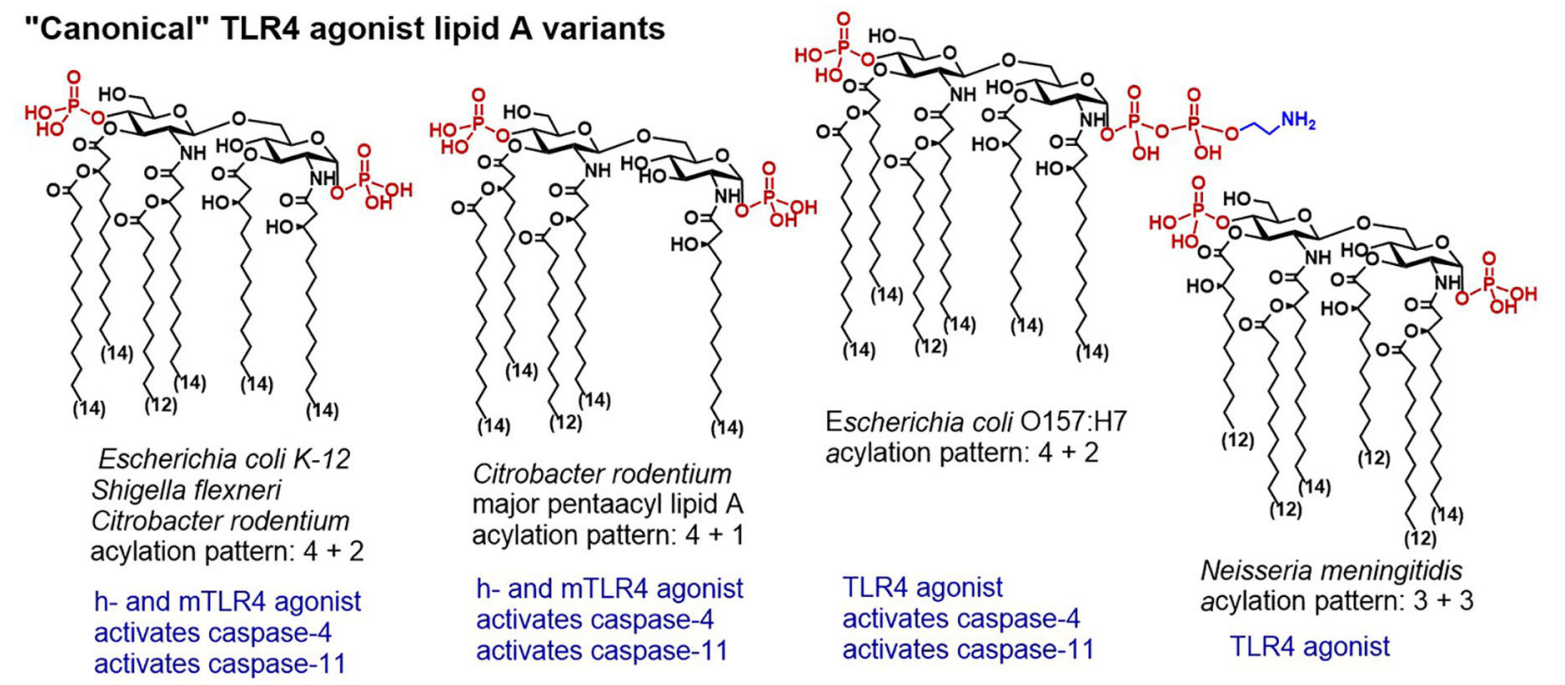

\section{Ara4N modified lipid A variants acting as TLR4 agonists}
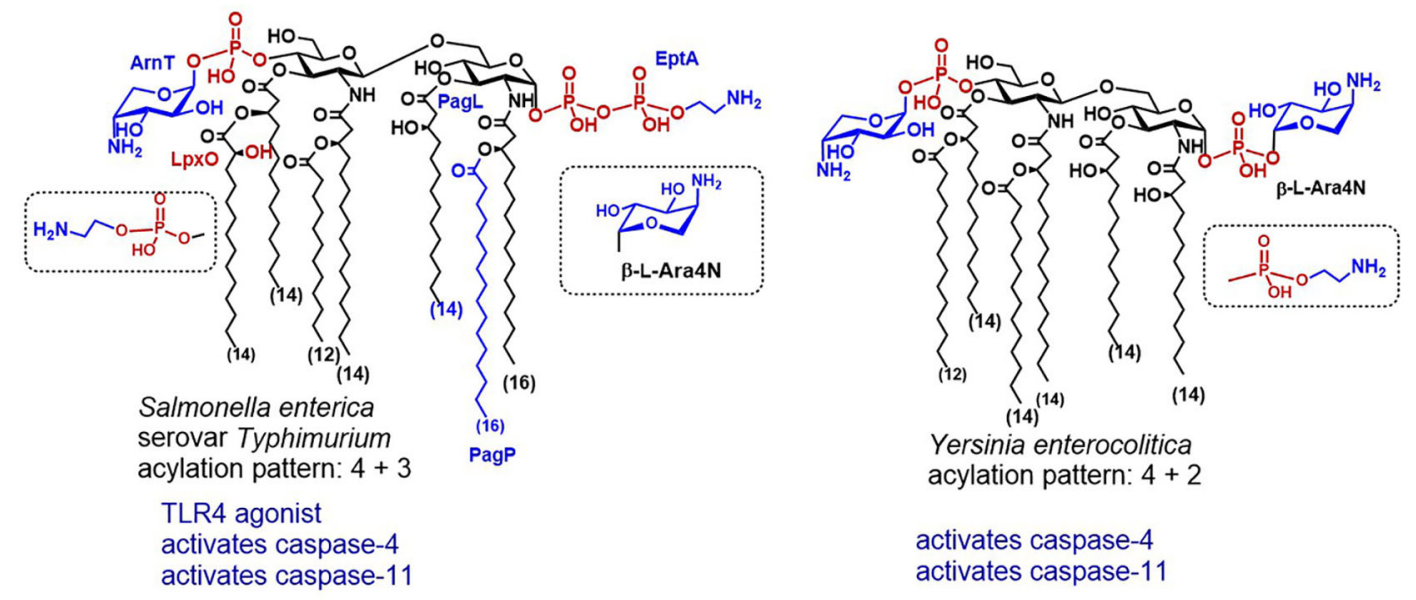

"Canonical" TLR4 antagonist or TLR4 inactive lipid A

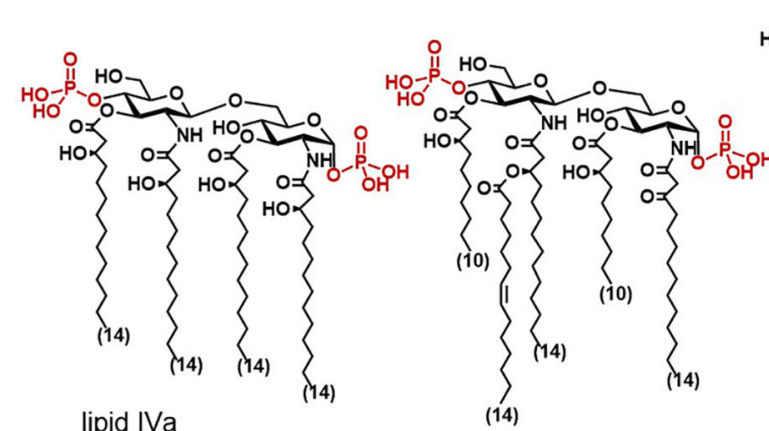

lipid IVa

Yersinia pestis $\left(37^{\circ} \mathrm{C}\right)$

acylation pattern: $2+2$

hTLR4 antagonist mTLR4 agonist caspase-4/11 inactive

Rhodobacter sphaeroides

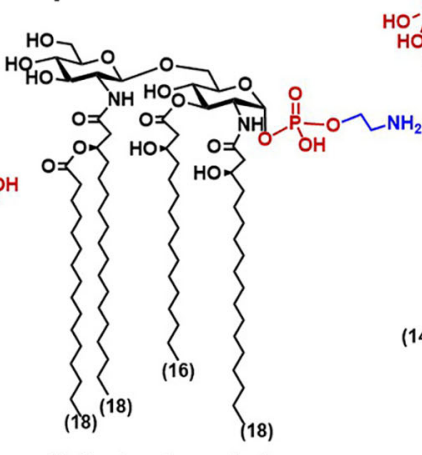

Helicobacter pylori

acylation pattern: $2+2$

TLR4 inactive or weak TLR4 antagonist

caspase-4/11 inactive or weak caspase- 11 antagonist

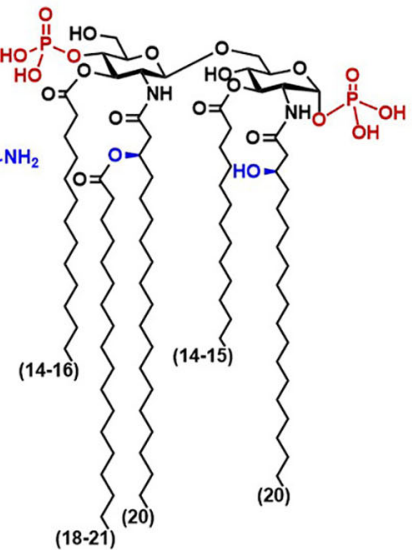

Chlamydia trachomatis acylation pattern: $3+2$

TLR4 inactive caspase-11 inactive

FIGURE 3 | Chemical structures of "canonical" TLR4 agonist and TLR4 antagonist lipid A variants and their caspase-4/11 specific activity (when known). 
lipid IVa to activate the non-canonical inflammasome in mice $(28,34)$. Several positively charged residues at the lipid A binding site of CARD were identified indispensable for efficient lipid Ainduced oligomerization (30). Interestingly, several lipid Abinding residues (K19, K52/R53, K62/K63/K64) are conserved in caspase- 4 but not in caspase- 11 which resembles speciesspecific differences between human and mouse MD-2. Whereas the rim of the binding pocket of human MD-2 is decorated by multiple Lys and Arg residues that are crucial for establishing ionic contacts with the lipid A phosphate groups, mouse MD-2 lacks most of these amino acids (6).

Along these lines, wt strain of E. coli induced expression of IL$1 \beta$ and pyroptosis in wt and TLR4 ${ }^{-/-}$BMDMs, whereas a mutant lipid IVa-producing strain induced TLR4-dependent production of IL-6 (which is consistent with weak agonist activity of lipid IVa at mTLR4), but not the release of IL-1 $\beta$ or pyroptosis in BMDMs (28). Activation of caspase-11 in BMDMs by transfected E. coli LPS was supressed when BMDMs were preloaded with underacylated Helicobacter lipid A (28) which is also known for its moderate antagonist activity at hTLR4 (159).

Another example of cytosolic bacteria producing LPS with canonical lipid A structure able to potently induce the TLR4dependent immune responses is S. flexneri-a Gram negative pathogen responsible for invasion, disruption and inflammatory destruction of the intestinal mucosa. S. flexneri synthesises heterogeneous hexa- to tetraacylated LPS having a "canonical" endotoxin acylation pattern $(4+2)$ (Figure 3) (160-162). Expectedly, hTLR4 was shown responsive to hexaacylated lipid A variants of $S$. flexneri, whereas mTLR4 was required to elicit TLR4-mediated NF- $\kappa \mathrm{B}$ response to penta-acylated mutants (163). Caspase-11 was responsive to LPS introduced by Shigella into the cytosol after bacteria escaped the vacuole. S. flexneri LPS induced production of IL-1 $\beta$ and pyroptotic cell death resulting in lethal endotoxemia in mice (89). Similarly, infection with $S$. flexneri was responsible for caspase- 4 driven inflammatory cell death in HaCaT keratinocytes and human colon adenocarcinoma HT29 cell line (164).

Juxtaposed, LPS from the obligatory intracellular pathogen $C$. trachomatis characterized by a "TLR4 inactive" acylation pattern $(3+2)$ of its lipid A (165) failed to activate the non-canonical inflammasome (166). Three out of five acyl chains in Chlamydia lipid A exceed the length that is considered optimal $\left(\mathrm{C}_{12}-\mathrm{C}_{14}\right)$ for the TLR4 activation (Figure 3). Both 2 - and $2{ }^{\prime}-N$-acyl chains as well as the secondary acyl chain at position $2^{\prime}$ of $C$. trachomatis lipid A have a length of up to 21 carbon atoms and the acyl chains that are ester-linked at positions 3- and 3'- are not hydroxylated. All these structural features confer low affinity to human TLR4/MD-2 complex $(167,168)$ and to the proteins of the LPS transfer cascade (169). Likewise, Chlamydia LPS failed to induce the dimerization of mouse TLR4/MD-2 complexes and to activate both NF- $\kappa \mathrm{B}$ and caspase-11-mediated signaling in BMDMs (166).

Thus, structure-activity relationships for caspase-4/11 and TLR4 activation seem to be somewhat similar: LPS possessing a "canonical" lipid A structure-hexaacylated/bisphosphorylatedbinds to CARD, promotes caspase- 4 and caspase- 11 oligomerization and induces caspase activation, whereas pentaand tetra-acylated lipid A variants fail to activate caspase-4/11 although can bind to CARD. Similar dependencies were recently demonstrated for synthetic lipid A mimetics close in structure to native lipid A molecules: tetraacylated disaccharide lipid A mimetics (DLAMs) acting as potent TLR4 antagonists did not induce caspase-4/11 proteolytic activity, while synthetic TLR4 agonists (DLAMs having picomolar affinity for TLR4/MD-2) were simultaneously very efficient in inducing oligomerization and proteolytic activity of caspase-4 in vitro (170). Intriguing results were obtained for the interaction of DLAMs with caspase11: despite causing caspase-11 oligomerization, several synthetic lipid A mimicking molecules did not induce caspase-11 catalytic activity which correlated with their chemical structure (170). Thus, the CARD of both capase- 4 and caspase- 11 was extraordinary sensitive to variations in the primary chemical structure (acylation and phosphorylation pattern) of lipid A mimicking molecules.

All these findings match with a 1:1 ligand-receptor stoichiometry already postulated for the assembly of TLR4/MD2/LPS complex, which insinuates a high affinity interaction of a single lipid A (or lipid A mimetic) molecule with the CARD. As far as the recognition process is concerned, both the primary chemical structure and the shape of aggregates formed by LPS/lipid A or lipid A mimetic could be involved. Indeed, the latter studies were performed in vitro using pore-limit native gel and relatively high lipid A/DLAMs concentrations. Since lipid A/LPS tend to form high molecular mass aggregates in a concentration-dependent manner (171, 172), DLAMs could also form aggregated structures which were, in turn, sensed by the CARDs of caspase4/11. Such interpretation would be in line with a recent study showing that caspase- 4 recognizes LPS-rich membrane interfaces. According to this study, caspase- 4 could bind directly to LPS-rich OMVs formed by N. meningitidis as well as to the high molecular mass aggregates of purified metabolically radiolabeled LPS (173175). Indeed, it has been demonstrated that purified caspase- 4 (C258A) and CARD domain from E. coli could bind huge LPS micelles and disaggregate them to small complexes in vitro (176).

Taking into account substantial differences in the molecular and physical properties of monomeric and aggregated structures of lipid A (2 kDa amphiphilic glycolipid) and LPS (20 kDa heterogeneous glycan) and the fact, that lipid A alone could induce pyroptosis in vivo (30) and could bind to CARD in vitro, we assume that the recognition of particular chemical entities of lipid A is essential for caspase-4/11-LPS interaction. Considering that lipid A is buried within the lipid bilayer to anchor LPS in the membranes or other liposomal interfaces and, therefore, not freely available for the interaction with proteins, an intermediate step preceding lipid A/ LPS-CARD interaction with involvement of additional proteins that can extract LPS from the membrane surfaces and deliver the lipid A fragment to CARD can be supposed. For example, TLR4/ MD-2 complex "exploits" accessory proteins LBP and CD14 to let the lipid A portion of LPS being directly "delivered" to the binding pocket of MD-2. Recent studies disclosed a fine-tuned mechanism of LPS sensing by inflammatory caspases with involvement of GBPs as supplementary proteins having high affinity for LPS $(98,136$, 157, 158). Similar to species-specific recognition of lipid A by the 
TLR4 system, some not yet fully understood species-dependent differences in the activation of human caspase- 4 and mouse caspase- 11 by LPS have been observed.

\section{WHAT ARE THE STRUCTURAL DETERMINANTS CRUCIAL FOR LPS/LIPID A RECOGNITION BY INFLAMMATORY CASPASES?}

To explore structure-activity relationships and to establish primary molecular signatures recognised by caspase-4/11 and involved in the non-canonical inflammasome activation, we analyzed the relevant literature from the "chemical" perspective with a special emphasis on particular structural features of LPS/lipid A mentioned in the studies on caspase-4/ 11 - and/or GBPs-mediated inflammasome activation. Remarkably, except for "canonical" hexaacylated lipid A of $E$. coli, S. flexneri and C. rodentium, the major lipid A species able to induce caspase- $4 / 11$ activation are characterized by specific lipid A modifications such as substitution of the phosphate groups by positively charged appendages (phosphoethanolamine or amino sugars) and by a specific acylation pattern (penta- to heptaacylated with fatty acids length up to 18 carbon atoms).

Covalent attachment of positively charged appendages to the phosphate groups of lipid A is considered a part of survival strategy of opportunistic Gram-negative bacteria. One of the most abundant phosphate group modifications-attachment of ethanolamine (Helicobacter) or phosphoethanolamine PNEt (EHEC, Salmonella) - is associated with bacterial resistance to cationic antimicrobial peptides (CAMPs) (177). In some species, the phosphate groups of lipid $A$ are substituted by cationic amino sugars-4-amino-4-deoxy- $\beta$-L-arabinose $(\beta$-L-Ara4N) in Burkholderia, Pseudomonas, Yersinia or Salmonella, or by galactosamine (Fransicella) or glucosamine (Bordetella) (178181). Inducible addition of $\beta$-L-Ara $4 \mathrm{~N}$ to the phosphate residues of lipid A is an adaptive mechanism that assists Gram-negative bacteria to oppose neutralization by CAMPs and to circumvent induction of the innate immune responses in the infected host. Despite rigorous research efforts, no explicit correlation between the presence of $\beta$-L-Ara $4 \mathrm{~N}$ as a lipid A phosphate group modification and the modulation of TLR4-dependent inflammation could be established $(182,183)$. To better comprehend the interrelation of caspase-4/11 activation and specific acylation and phosphorylation pattern of lipid $A$, we provide a short exposè on structural features of lipid A produced by bacterial species that are known to induce caspase-4/11mediated inflammasome activation and/or TLR4 dependent signaling with special emphasis on LPS remodeling.

\section{Activation of Inflammatory Caspases by Extracellular Bacteria That Produce TLR4- Agonist LPS Variants}

Caspase-4 activating E. coli strain O157:H7 (enterohaemorrhagic E. coli, EHEC) produces 1-O-P-PNEt lipid A which differs from a "classic" lipid A (hexaacylated, bis-phosphorylated, to one-third substituted with pyrophosphate at position 1)synthesised by E. coli serotypes K12 and O111:B4. The occurrence of the phosphoethanolamine modification at the glycosidic phosphate group P-1 in EHEC has been distinctively confirmed (184). EHEC and EPEC (enteropathogenic E. coli) strains were shown to activate caspase- $4(133,164)$, to induce caspase-4/11-mediated IL- $1 \beta$ and IL-18 secretion and inflammatory cell death, whereas specific T3SS effector protein could inhibit caspase-4/11-dependent inflammasome $(185,186)$. Whether 1-O-P-PEtN motif of the lipid A fragment of LPS is functionally involved in EHECinduced caspase-4/11 dependent inflammasome activation remains for now unknown.

C. rodentium is a murine Gram-negative bacterium used as a surrogate to study human non-invasive gastrointestinal pathogens EPEC and EHEC since it causes similar transmissible diarrheal disease in mice. The lipid A acylation pattern of Citrobacter LPS is identical to that of $E$. coli with exception of relatively high proportion of the penta-acylated species having both $3+2$ and 4 +1 acylation pattern, whereas the latter is more abundant (Figure 3) (187). In agreement with the known principle for "TLR4 agonist" acylation pattern of lipid A, C. rodentium induces rapid TLR4dependent responses in intestinal epithelium, although TLR4mediated pro-inflammatory signaling is not host-protective and contributes to pathology and morbidity during infection (188). TLR4 was demonstrated particularly important for NLRP3 inflammasome activation in $C$. rodentium and $E$. coli infected mouse macrophages. Importantly, the TLR4/TRIF axisregulated expression of caspase-11 was indispensable for $E$. coliand $C$. rodentium -induced NLRP3 inflammasome activation in macrophages (96). Thus, extracellular enteric bacteria must be recognized by both TLR4- and caspase-11 to induce the noncanonical inflammasome activation and pyroptosis. Like pathogenic human-specific E. coli strains EPEC and EHEC, C. rodentium modifies the phosphate groups of its lipid A with phosphoethanolamine. This covalent modification is primarily catalysed by specific transferases PmrC and CptA, the expression of which is regulated by PmrAB. Interestingly, PEtN modification contributed to maintenance of OMV integrity, but simultaneously negatively affected the rate of production of OMV by $C$. rodentium (189).

Yersinia species evolved many strategies to evade the recognition by the human innate immune system, including inducible LPS remodeling. To achieve a suppression of local and systemic inflammation, $Y$. pestis modifies the acylation degree of the diglucosamine backbone of its lipid A from hexaacylated (hTLR4 agonist) to tetraacylated (inactive or hTLR4 antagonist). Thus, the lipid A produced by Yersiniae in mammalian host at $37^{\circ} \mathrm{C}$ is underacylated and similar in structure to lipid IVa which deprives Yersinia LPS the hTLR4-mediated activity (Figure 3) (190). Mutants producing hexaacylated lipid A (normally synthesised by bacteria in a vector host at $25^{\circ} \mathrm{C}$ ) have been shown to strongly activate the innate immune response in a TLR4-dependent manner (191). Recognition of lipid A by caspase-11 might follow similar structure-activity relationships: transfection of hexaacylated LPS from $Y$. pestis grown at $25^{\circ} \mathrm{C}$ 


\section{TLR4 inactive lipid A that activate caspase-4/11}

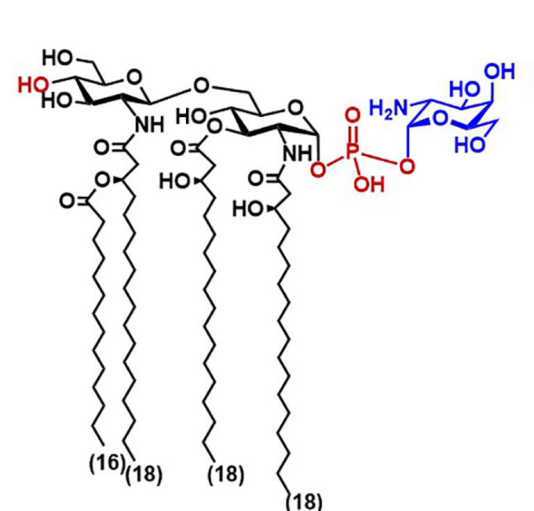

Francisella tularensis, F. novicida acylation pattern: $2+2$

TLR4 inactive activates caspase-4 caspase-11 inactive

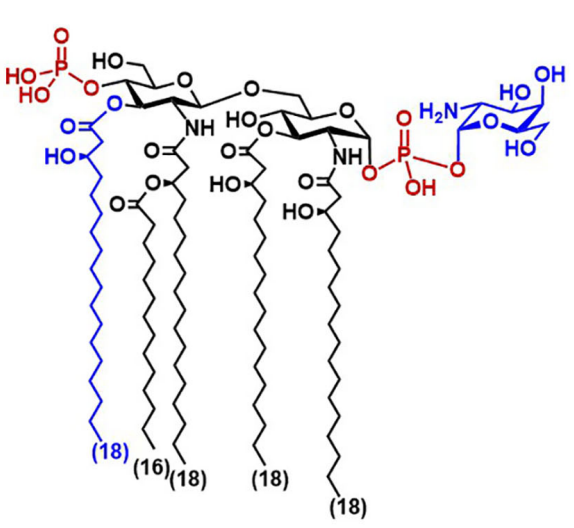

Francisella IpxF mutant acylation pattern: $3+2$

TLR4 inactive activates caspase-11

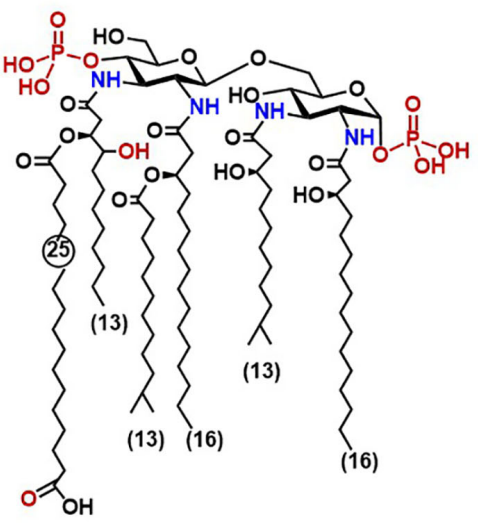

Legionella pneumophila acylation pattern: $4+2$

TLR4 inactive activates caspase-4 activates caspase-11
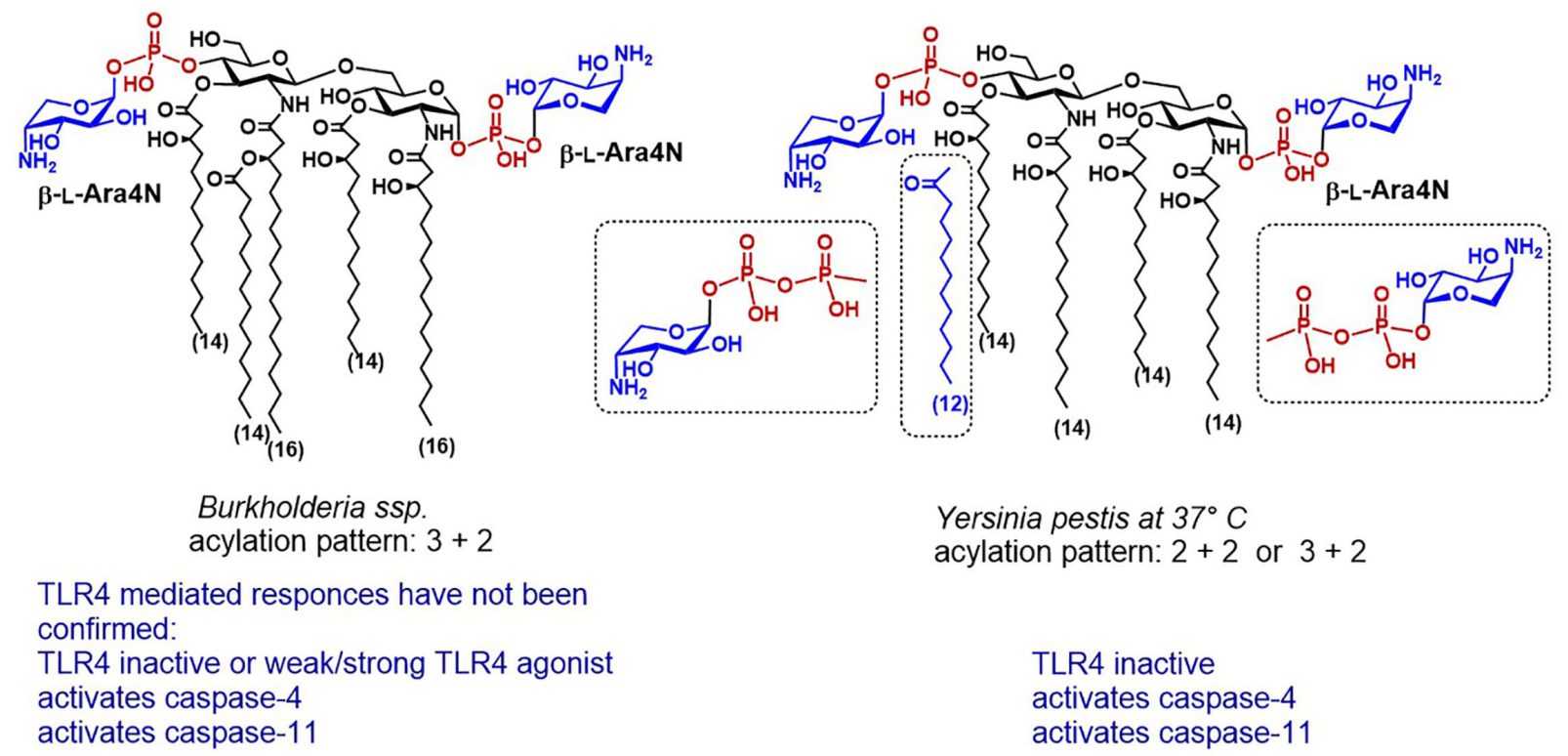

Yersinia pestis at $37^{\circ} \mathrm{C}$ acylation pattern: $2+2$ or $3+2$

TLR4 mediated responces have not been confirmed:

TLR4 inactive or weak/strong TLR4 agonist activates caspase-11

TLR4 inactive activates caspase- 4 activates caspase-11

FIGURE 4 | Chemical structures of lipid A variants that do not activate TLR4/MD-2 but are distinguished by a confirmed caspase-4 or caspase-11 mediated activity.

induced caspase-11-mediated cytotoxicity in mouse macrophages whereas transfection of tetra-acylated LPS from bacteria grown at $37^{\circ} \mathrm{C}$ did not (34).

Apart from $Y$. pestis-a facultative intracellular Gramnegative bacterium, and causative agent of bubonic plague, two other Yersinia species: Y. enterocolitis and Y. pseudotuberculosis are pathogenic to humans and cause foodborne infections leading to gastroenteritis and septicemia. The structure of $Y$. pseudotuberculosis lipid A is the closest to Y. pestis, as far as the acylation pattern and Ara4N modification is concerned (192).
The mechanism of Ara4N modification of lipid A Y. pestis is different and more complex than in other bacteria, and the Ara4N modification has been shown to play a crucial role in both transmission and survival of $Y$. pestis in its flea vector and in pathogenicity to human host $(193,194)$. Both or one phosphate groups of $Y$. pseudotuberculosis lipid A are covalently substituted by Ara $4 \mathrm{~N}$, and the $\mathrm{C}_{14}$ acyloxyacyl chain at position 2 is esterified by palmitoylation $\left(\mathrm{C}_{16}\right)$ (Figures 3,4$)$. Y. enterocolitica entails a shorter secondary acyl chain in position $2\left(\mathrm{C}_{12}\right.$ or $\left.\mathrm{C}_{14}\right)$. The functional role of inducible addition of Ara4 $\mathrm{N}$ to the phosphate 
residues of lipid A in Yersinia as well the propensity of its LPS to induce caspase-4/11-mediated pyroptosis has not yet been adequately studied. It has been recently reported that Yersinia infection induces caspase- 8 mediated pyroptosis which proceeds through cleavage of Gasdermin D, although the involvement of LPS in this process has not been illustrated $(195,196)$. Temperature-regulated remodeling of lipid A in Yersinia substantially complicates studies of Yersinia LPS-induced pathogenicity in vivo, since tetraacylated lipid A variants produced by Yersinia at $37^{\circ} \mathrm{C}$ might act as TLR4 antagonists in human, simultaneously performing as weak TLR4 agonists in the mouse system. Indeed, the induction of the TLR4/MD-2/LPSmediated protective responses in mice was responsible for reduced sensitivity of rodents to Yersinia infection and indicated a necessity for exploring Yersinia virulence factors in humanized mouse models (197).

\section{LPS-Induced TLR4- and Caspase-4/11- Mediated Responses to Intracellular Gram-Negative Bacteria That Escape the Vacuole}

Salmonella and Legionella are intracellular enteric pathogens known to cause gastroenteritis that can result in a systemic disease. These strains were shown to release specific bacterial antigens into the host cell cytosol and to trigger inflammasome activation within epithelial cells and macrophages $(134,198)$.

The disaccharide backbone of L. pneumophila lipid A contains two 2-diamino-2-dideoxyglucose $(\mathrm{GlcN} 3 \mathrm{~N})$ residues instead of common 2-amino-2-deoxyglucose $(\mathrm{GlcN})$ and the four amino groups are substituted by two long-chain $\left(C_{16}\right) \beta$ hydroxyacyl residues, one of which is further acylated by a branched $\mathrm{C}_{14}$ lipid chain, whereas the amino group in position 3 'entails unusual long-chain $\left(\mathrm{C}_{25}\right)$ fatty acid (Figure 4) (199, 200). According to the well-establised structure-activity relationships, lipid A having acyl chains longer than $\mathrm{C}_{14}$ have usually much lower affinity to MD-2/TLR4 complex and to LBP than lipid As with a "classic" $\mathrm{C}_{12}-\mathrm{C}_{14}$ acylation pattern. Indeed, the unusual structure of $L$. pneumophila lipid A accounted for the absence of TLR4-dependent endotoxic activity, due to a failure to interact with both TLR4/MD-2 complex and CD14 (201). Although L. pneumophila harbors a gene conferring resistance to cationic antimicrobial peptides, the modification of the phosphate groups of its lipid A with cationic residues has not yet been confirmed by structural analysis (202). Infection with L. pneumophila induced rapid caspase-11-mediated pyroptosis in mouse macrophages which has been accelerated by deletion of a specific effector supporting the integrity of Legionella-containing vacuole $(135,203)$.

Salmonella can alter the structure of its lipid A and remodel the content of the bacterial outer membrane by using several regulatory systems that govern phosphate group modifications crucial for resistance to CAMPs (204). Complex mechanisms which involve several regulatory proteins are implicated in the control of these processes. S. enterica serovar Typhimurium strains possess specific two-component systems that can add $\beta$ -
L-Ara4N to the lipid A phosphate groups or induce 3-Odeacylation at the proximal $\mathrm{GlcN}$ residue (Figure 4). The former modification promotes bacterial resistance to antimicrobial peptides, whereas the latter enhances the host recognition of lipid A by TLR4 (205). In particular, the PhoPQ two-component system regulates $\mathrm{PagP}$-catalyses addition of a secondary palmitate residue at position 2 of the proximal GlcN moiety, and PagL-induces 3-O-deacylation, whereas $\mathrm{PmrAB}$ regulates the addition of Ara4N and phosphoethanolamine (206-208). Addition of Ara4N to lipid A inhibits the enzymatic activity of PagL which results in the synthesis of heptaacylated lipid A with Ara4N-modified phosphate groups (207). Heptaacylated S. Typhimurium lipid A has reduced hTLR4 activating potential, whereas its 3-O-deacylated counterpart (acylation pattern $4+2$ ) belongs to the most powerful activators of hTLR4. Juxtaposed, in mouse TLR4 system heptaacylated S. Typhimurium LPS isolates induce robust IL-6 production in BMDMs (28).

Not surprisingly, Salmonella is able to activate the noncanonical capase- 4 and caspase-11 dependent inflammasomes via intracellular LPS sensing $(28,133,209)$. Whether and how the structure of S. Typhimurium lipid A and the presence of positively charged appendages at the phosphate groups influence caspase-4/11-LPS interaction remains to be determined.

\section{Structural Peculiarities of Francisella LPS Accountable for Species-Specific Caspase-4/11 Activation and TLR4 Escape}

The major lipid A of Francisella possesses a unique tetraacylated structure lacking the $4^{\prime}$-phosphate group and the $3^{\prime}$-acyl chain and containing an $\alpha-D-G a l N$ residue at the glycosidically linked phosphate group (Figure 4) (210). All subspecies of genus F. tularensis (Schu S4, holartica, live vaccine strain LVS (attenuated type B strain), as well as a nonvirulent laboratory strain $F$. novicida) retain analogous lipid A modified with phosphodiester linked GalN at the glycosidic phosphate group P-1 (180, 211-213). The modification of Francisella lipid A phosphate residue with GalN is associated with augmented bacterial virulence and resistance to CAMPs, although the consequence of this modification for Francisella LPS/lipid A recognition by the innate immune system of the host has not yet been fully clarified. Mutants deficient in GalN modification were shown to induce activation of the innate immune responses in mice and to have weakened pathogenicity (214).

Francisella LPS escapes the recognition by both TLR4/MD-2 complex and LBP due to its hypoacylated structure which is assembled in a temperature-dependent manner (215), the inappropriate length of its four lipid chains $\left(\mathrm{C}_{18}-\mathrm{C}_{16}\right)$ and the absence of a phosphate group at the distal GlcN moiety (P-4') (216-218). Also, penta-acylated Francisella lpxF mutant failed to activate TLR4 which was explained by a non-optimal length of its acyloxy- and acyloxyacyl chains, although this mutant displayed attenuated virulence. Thus, the structural features of Fransisella lipid A do not comply with the well-establish requirements for the lipid A sensing by TLR4/MD-2. The lack of TLR4 stimulating potential of tetraacylated Francisella LPS is compensated by the 
activation of NOD-like receptors (NLRs), and the adaptor molecule ASC which are involved in the regulation of caspase1 -mediated inflammasome activation $(219,220)$, as well as by the GBPs-promoted activation of AIM2 (Interferon-inducible protein AIM2 also known as "absent in melanoma 2") inflammasome in mice $(221,222)$. Thus, TLR4 signaling plays comparatively insignificant role in defence against Francisella infection or in protection after administration of live vaccine strain LVS in mice $(223,224)$.

The nonvirulent laboratory strain F. novicida as well as several other Francisella strains exhibit a truncated lipopolysaccharide form deprived of the polymeric $\mathrm{O}$-antigen and the core sugars. A bifunctional Kdo-hydrolase, an LPS remodeling enzyme responsible for the synthesis of truncated LPS structures, has been identified in the inner membrane of $F$. novicida $(155,156,225,226)$. Thus, around $90 \%$ of $F$. novicida LPS consists of a solely tetraacylated lipid A modified with $\alpha$-DGalN at the glycosidic phosphate group P-1 (Figure 4) (227). A recent study postulated that tetra-acylated LPS/lipid A of F. novicida can be detected by caspase- 4 upon LPS transfection in human monocyte-derived macrophages (151). Although transfected F. novicida LPS was 10-fold less potent compared to (transfected) E. coli LPS to induce activation of caspase-4, the innate immune responses to $F$. novicida LPS (i.e. IL- $1 \beta$ release and cell death) were fully caspase- 4 driven. Importantly, these responses were essentially GBP2-dependent, highlighting a crucial role of guanylate binding proteins in facilitating recognition of cytosolic lipid A/LPS structures by inflammatory caspases. Similar to the TLR4/MD-2 complex, caspase- 4 and caspase- 11 exhibit species-specific differences in sensing underacylated lipid A which escapes caspase-11 recognition. The disparities in sensing structurally different lipid A molecules might be due to dissimilarities between the CARD domains of caspase- 4 and caspase- 11 , which share $51 \%$ identity. Accordingly, tetraacylated Fransicella lipid A could not be detected by caspase-11 after F. novicida LPS transfection in mouse macrophages (34). However, transfection of pentaacylated Francisella LPS (lpxF mutant) that retains the phosphate moiety at position $4^{\prime}$ and the $N$-linked $\mathrm{C}_{16}-\mathrm{C}_{18}$ fatty acid at position $3^{\prime}$ of the diglucosamine backbone $(210,228)$ resulted in a robust caspase- 11 activation followed by pyroptosis. Thus, caspase- 4 seem to be more receptive to the number of phosphate groups decorating the diglucosamine backbone of lipid A than to the acylation pattern, both in respect to the length and number of acyl chains. These data provide unequivocal evidence for the primary role of lipid A in driving the activation of caspase-4/11 and for apparently high affinity interaction of particular structural elements of lipid A with caspase-4/ 11 CARD.

\section{Detection of Ara4N Modified Burkholderia LPS in the Cytosol of Mammalian Cells}

The lipid A phosphate groups of clinical isolates of Burkholderia are substituted by an amino sugar $\beta-\mathrm{L}-\mathrm{Ara} 4 \mathrm{~N}$ that is believed to reduce the net negative charge of the bacterial membrane and confer resistance to antibiotics. Host-adapted Burkholderia species cause severe pneumonia and systemic endotoxemia in cystic fibrosis and melioidosis patients which is linked to a potent cytokine-inducing capacity of Burkholderia LPS. Substitution of both phosphate groups with Ara4N was confirmed for ubiquitous environmental Burkholderia strain $B$. pseudomallei-an opportunistic facultative intracellular pathogen causing melioidosis in humans, as well as for a less virulent strain B. thailandensis (229-232). Notwithstanding its underacylated, heterogeneous tetra- and penta-acylated lipid A (233), LPS isolates from B. cepacia, B. dolosa, B. cenocepacia, B. mallei, and $B$. multivorans were reported to potently induce TLR4 mediated NF- $\mathrm{\kappa B}$ signalling (234-237). The molecular background for a robust induction of the pro-inflammatory signaling by underacylated Ara4N-modified Burkholderia lipid A/LPS isolates is not yet clarified, particularly, because only hexaacylated lipid A patterns with fatty chain length 12-14 carbon atoms are known to elicit efficient TLR4-mediated responses (183). Whether the presence of Ara4N modification at both phosphate groups renders Burkholderia LPS to a strong TLR4 agonist is not yet proven, although mono-substitution of P-1 with Ara4N ( $1-\mathrm{O}-\mathrm{P}-\beta$-L-Ara4N) did not significantly enhance the cytokine-inducing capacity of synthetic Burkholderia lipid A in vitro (182).

Since penta-acyl Burkholderia lipid A is structurally "unsuitable" to function as potent TLR4 agonist, it is rational to assume that other LPS sensing proteins could be responsible for recognition of Burkholderia LPS patterns. Indeed, it has been reported that caspase- 11 activation by $B$. thailandensis and $B$. pseudomallei protected mice from lethal infection outcome (135). Newest reports demonstrated caspase-11 promoted cell death induced by wild type B. thailandensis (lipid A is penta-acylated, modified with Ara4N), whereas tetraacylated mutants lost the ability to activate TLR4 and had 30\% lower capacity in induction of caspase-11 dependent pyroptosis (229). Infection with $B$. thailandensis triggered caspase- 1 mediated release of IL- $1 \beta$ and IL-18 and caspase-11 induced activation of the NLRP3 inflammasome leading to death of infected lung epithelial cells by pyroptosis in mice $(238,239)$. Further studies revealed speciesspecific differences in the activation modalities of caspase- 11 and caspase -4 by $B$. thailandensis. In rodents, the activation of caspase1 provoked the release of IL-18 which, in turn, induced IFN- $\gamma$ to prime caspase- 11 activity, whereas caspase- 4 transgenic mice did not necessitate IFN- $\gamma$ priming upstream of caspase- 4 to control the infection (240). The significance of caspase- 4 activation implicated in the formation of autophagosomes was also confirmed for $B$. cenocepacia infected macrophages (241). Thus, TLR4 seem not to belong to the primary PRR able to sense penta-acylated Burkholderia LPS, rather this function is taken over by the cytosolic LPS receptors such as caspase-4/11 and GBP, or other not-yet-identified proteins.

\section{CONCLUSION}

The LPS induced TLR4-mediated signaling and caspase-4/11 activation drives the assembly of inflammasomes and contributes 
to development of inflammation, thus, mounting a beneficial defensive host immune response against infectious challenge. Juxtapose, in the conditions of unresolved inflammation, TLR4 and caspase-4/11 activation can result in the amplified innate immune signaling, systemic overexpression of the proinflammatory mediators and pyroptosis which prompts the onset of sepsis syndrome and a fatal septic shock $(15,22,38,88)$.

Whereas LPS-induced TLR4 complex dimerization results in the expression and release of MyD88- and TRIF-dependent cytokines such as TNF- $\alpha$ and interleukins activation of inflammatory caspases-4/11 by LPS arbitrates the release of IL$1 \beta$ and IL-18, Gasdermin-mediated pyroptosis and is associated with high lethality $(242,243)$. In vivo, activation of caspase- 11 has been shown to provide protection against bacterial infections (135), but also to cause morbidity and mortality in a mouse model of endotoxemia $(28,34)$. Thus, inhibition of both TLR4 and caspase-4/11 activation could provide instruments to control acute inflammation and to reduce the LPS-induced toxic effects. Concurrently, coordinated induction of the pro-inflammatory signaling via TLR4 and/or caspase-4/11 pathways is believed to mount an advantageous immune activation aimed at protection from infection and management of chronic inflammation. Thus, modulation of the innate immune responses by application of TLR4 and/or caspase-4/11 agonists or partial agonists could be a promising therapeutic approach.

Although inflammatory caspases-4/11 can directly bind the lipid A moiety of LPS, the precise molecular mechanism and the structural basis for this recognition is not yet fully understood. Caspase-4/11 exhibit somewhat different requirements to the structure of LPS compared to the TLR4 complex and seem to be more receptive to the number of phosphate groups decorating

\section{REFERENCES}

1. Ishii KJ, Koyama S, Nakagawa A, Coban C, Akira S. Host innate immune receptors and beyond: making sense of microbial infections. Cell Host Microbe (2008) 3:352-63. doi: 10.1016/j.chom.2008.05.003

2. Ulevitch RJ, Tobias PS. Recognition of Gram-negative bacteria and endotoxin by the innate immune system. Curr Opin Immunol (1999) 11 (1):19-22. doi: 10.1016/S0952-7915(99)80004-1

3. Schumann RR, Leong SR, Flaggs GW, Gray PW, Wright SD, Mathison JC, et al. Structure and function of lipopolysaccharide binding protein. Science (1990) 249(4975):1429-31. doi: 10.1126/science.2402637

4. Ryu JK, Kim SJ, Rah SH, Kang JII, Jung HE, Lee D, et al. Reconstruction of LPS transfer cascade reveals structural determinants within LBP, CD14, and TLR4-MD2 for efficient LPS recognition and transfer. Immunity (2017) 46 (1):38-50. doi: 10.1016/j.immuni.2016.11.007

5. Park BS, Song DH, Kim HM, Choi BS, Lee H, Lee JO. The structural basis of lipopolysaccharide recognition by the TLR4-MD-2 complex. Nature (2009) 458:1191-5. doi: 10.1038/nature07830

6. Ohto U, Fukase K, Miyake K, Shimizu T. Structural basis of species-specific endotoxin sensing by innate immune receptor TLR4/MD-2. Proc Natl Acad Sci USA (2012) 109(19):7421-6. doi: 10.1073/pnas.1201193109

7. Hammad H, Chieppa M, Perros F, Willart MA, Germain RN, Lambrecht $\mathrm{BN}$. House dust mite allergen induces asthma via Toll-like receptor 4 triggering of airway structural cells. Nat Med (2009) 15(4):410-6. doi: $10.1038 / \mathrm{nm} .1946$

8. Abdollahi-Roodsaz S, Joosten LAB, Roelofs MF, Radstake TRDJ, Matera G, Popa C, et al. Inhibition of Toll-like receptor 4 breaks the inflammatory loop the glucosamine backbone of lipid A than to the acylation pattern, especially in respect to number and length of acyl chains. LPSremodeling resulting in decoration of the phosphate groups of lipid A with positively charged appendages has not yet been specifically addressed in biochemical and structural studies of caspase-4/11 ligand specificities, however, our analysis suggests that these modifications could be essential for LPS/lipid A sensing by inflammatory caspases and related proteins such as GBPs. Importantly, the well-known species-specific differences in sensing lipid A variants by human and mouse TLR4 also seem to apply for caspase-4/11. For instance, caspase- 4 displays much broader reactivity in sensing underacylated LPS compared to caspase-11, which might have important consequences for translation in vivo studies to clinical trials. Although the structural basis of lipid A/LPS recognition by inflammatory caspases is not yet completely defined, and many questions still remain unanswered, further studies will certainly decipher particular molecular signatures conferring LPS responsiveness to caspase- $4 / 11$.

\section{AUTHOR CONTRIBUTIONS}

$\mathrm{AZ}$ and $\mathrm{HH}$ have written the manuscript. All authors contributed to the article and approved the submitted version.

\section{FUNDING}

Financial support from Austrian Science Fund FWF grants P-28915 and P-32397 is gratefully acknowledged.

in autoimmune destructive arthritis. Arthritis Rheumatol (2007) 56 (9):2957-67. doi: 10.1002/art.22848

9. Abreu MT, Arditi M. Innate immunity and toll-like receptors: clinical implications of basic science research. J Pediatr (2004) 144(4):421-9. doi: 10.1016/j.jpeds.2004.01.057

10. Zakeri A, Russo M. Dual Role of Toll-like Receptors in Human and Experimental Asthma Models. Front Immunol (2018) 9:1027. doi: 10.3389/fimmu.2018.01027

11. Zuo L, Lucas K, Fortuna CA, Chuang CC, Best TM. Molecular Regulation of Toll-like Receptors in Asthma and COPD. Front Physiol (2015) 6:312. doi: 10.3389/fphys.2015.00312

12. Shalaby KH, Al Heialy S, Tsuchiya K, Farahnak S, McGovern TK, Risse PA, et al. The TLR4 and TRIF pathway can protect against the development of experimental allergic asthma. Immunology (2017) 152(1):138-49. doi: 10.1111/imm.12755

13. Frantz S, Ertl G, Bauersachs J. Mechanisms of disease: Toll-like receptors in cardiovascular disease. Nat Clin Pract Cardiovasc Med (2007) 4(8):444-54. doi: $10.1038 /$ ncpcardio0938

14. Michaud JP, Hallé M, Lampron A, Thériault P, Préfontaine P, Filali M, et al. Toll-like receptor 4 stimulation with the detoxified ligand monophosphoryl lipid A improves Alzheimer's disease-related pathology. Proc Nati Acad Sci USA (2013) 110:1941-6. doi: 10.1073/pnas.1215165110

15. Rittirsch D, Flierl MA, Ward PA. Harmful molecular mechanisms in sepsis. Nat Rev Immunol (2008) 8(10):776-87. doi: 10.1038/nri2402

16. Kissoon N, Daniels R, van der Poll T, Finfer S, Reinhart K. Sepsis-the final common pathway to death from multiple organ failure in infection. Crit Care Med (2016) 44(6):e446. doi: 10.1097/CCM.0000000000001582 
17. Hwang YH, Lee Y, Paik MJ, Yee ST. Inhibitions of HMGB1 and TLR4 alleviate DINP-induced asthma in mice. Toxicol Res (2019) 8(5):621-9. doi: 10.1039/c9tx00048h

18. Tang H, Li T, Han X, Sun J. TLR4 antagonist ameliorates combined allergic rhinitis and asthma syndrome (CARAS) by reducing inflammatory monocytes infiltration in mice model. Int Immunopharmacol (2019) 73:254-60. doi: 10.1016/j.intimp.2019.05.021

19. Shirey KA, Lai W, Scott AJ, Lipsky M, Mistry P, Pletneva LM, et al. The TLR4 antagonist Eritoran protects mice from lethal influenza infection. Nature (2013) 497(7450):498-502. doi: 10.1038/nature12118

20. Younan P, Ramanathan P, Graber J, Gusovsky F, Bukreyev A. The Toll-Like Receptor 4 Antagonist Eritoran Protects Mice from Lethal Filovirus Challenge. mBio (2017) 8(2):e00226-17. doi: 10.1128/mBio.00226-17

21. Reisser D, Jeannin J-F. Lipid A in cancer therapies: preclinical studies. In: J-F Jeannin, editor. Lipid $A$ in cancer therapy. New York: Springer, Landes Bioscience (2009). pp. 101-110. doi: 10.1007/978-1-4419-1603-7_9

22. Opal SM. The host response to endotoxin, antilipopolysaccharide strategies, and the management of severe sepsis. Int J Med Microbiol (2007) 297 (5):365-77. doi: 10.1016/j.ijmm.2007.03.006

23. Iwasaki A, Medzhitov R. Toll-like receptor control of the adaptive immune responses. Nat Immunol (2004) 5(10):987-95. doi: 10.1038/ni1112

24. Kabelitz D, Medzhitov R. Innate immunity - cross-talk with adaptive immunity through pattern recognition receptors and cytokines. Curr Opin Immunol (2007) 19(1):1-3. doi: 10.1016/j.coi.2006.11.018

25. Casella C, Mitchell T. Putting endotoxin to work for us: Monophosphoryl lipid A as a safe and effective vaccine adjuvant. Cell Mol Life Sci (2008) 65 (20):3231-40. doi: 10.1007/s00018-008-8228-6

26. Ishizaka ST, Hawkins LD. E6020: a synthetic Toll-like receptor 4 agonist as a vaccine adjuvant. Expert Rev Vaccines (2007) 6(5):773-84. doi: 10.1586/ 14760584.6.5.773

27. Johnson DA. Synthetic TLR4-active glycolipids as vaccine adjuvants and stand-alone immunotherapeutics. Curr Top Med Chem (2008) 8(2):64-79. doi: $10.2174 / 156802608783378882$

28. Kayagaki N, Wong MT, Stowe IB, Ramani SR, Gonzalez LC, AkashiTakamura S, et al. Noncanonical inflammasome activation by intracellular LPS independent of TLR4. Science (2013) 341(6151):1246-9. doi: 10.1126/ science. 1240248

29. Broz P, Ruby T, Belhocine K, Bouley DM, Kayagaki N, Dixit VM, et al. Caspase-11 increases susceptibility to Salmonella infection in the absence of caspase-1. Nature (2012) 490(7419):288-91. doi: 10.1038/nature11419

30. Shi J, Zhao Y, Wang Y, Gao W, Ding J, Li P, et al. Inflammatory caspases are innate immune receptors for intracellular LPS. Nature (2014) 514:187-92. doi: 10.1038/nature13683

31. Casson CN, Yu J, Reyes VM, Taschuk FO, Yadav A, Copenhaver AM, et al. Human caspase-4 mediates noncanonical inflammasome activation against gram-negative bacterial pathogens. Proc Nat Acad Sci USA (2015) 112 (21):6688-93. doi: 10.1073/pnas.1421699112

32. Kayagaki N, Warming S, Lamkanfi M, Walle LV, Louie S, Dong J, et al. Noncanonical inflammasome activation targets caspase-11. Nature (2011) 479 (7371):117-21. doi: 10.1038/nature10558

33. Rathinam VAK, Vanaja SK, Waggoner L, Sokolovska A, Becker C, Stuart LM, et al. TRIF Licenses Caspase-11-Dependent NLRP3 Inflammasome Activation by Gram-Negative Bacteria. Cell (2012) 150(3):606-19. doi: 10.1016/j.cell.2012.07.007

34. Hagar JA, Powell DA, Aachoui Y, Ernst RK, Miao EA. Cytoplasmic LPS activates caspase-11: implications in TLR4-independent endotoxic shock. Science (2013) 341(6151):1250-3. doi: 10.1126/science.1240988

35. Kagan JC. Sensing endotoxins from within. Science (2013) 341(6151):11845. doi: 10.1126/science.1243939

36. Hagar JA, Aachoui Y, Miao EA. WildCARDs: Inflammatory caspases directly detect LPS. Cell Res (2015) 25(2):149-50. doi: 10.1038/cr.2014.128

37. Gao Y-L, Zhai J-H, Chai Y-F. Recent Advances in the Molecular Mechanisms Underlying Pyroptosis in Sepsis. Mediators Inflamm (2018) 2018:5823823. doi: 10.1155/2018/5823823

38. Napier BA, Brubaker SW, Sweeney TE, Monette P, Rothmeier GH, Gertsvolf NA, et al. Complement pathway amplifies caspase-11-dependent cell death and endotoxin-induced sepsis severity. J Exp Med (2016) 213(11):2365. doi: $10.1084 /$ jem. 20160027
39. Pfalzgraff A, Weindl G. Intracellular Lipopolysaccharide Sensing as a Potential Therapeutic Target for Sepsis. Trends Pharmacol Sci (2019) 40 (3):187-97. doi: 10.1016/j.tips.2019.01.001

40. Vandanmagsar B, Youm Y-H, Ravussin A, Galgani JE, Stadler K, Mynatt RL, et al. The NLRP3 inflammasome instigates obesity-induced inflammation and insulin resistance. Nat Med (2011) 17(2):179-88. doi: 10.1038/nm.2279

41. Duewell P, Kono H, Rayner KJ, Sirois CM, Vladimer G, Bauernfeind FG, et al. NLRP3 inflammasomes are required for atherogenesis and activated by cholesterol crystals. Nature (2010) 464(7293):1357-61. doi: 10.1038/ nature 08938

42. Halle A, Hornung V, Petzold GC, Stewart CR, Monks BG, Reinheckel T, et al. The NALP3 inflammasome is involved in the innate immune response to amyloid- $\beta$. Nat Immunol (2008) 9(8):857-65. doi: 10.1038/ni.1636

43. Heneka MT, Kummer MP, Stutz A, Delekate A, Schwartz S, Vieira-Saecker A, et al. NLRP3 is activated in Alzheimer's disease and contributes to pathology in APP/PS1 mice. Nature (2013) 493(7434):674-8. doi: 10.1038/ nature 11729

44. Kawai T, Adachi O, Ogawa T, Takeda K, Akira S. Unresponsiveness of MyD88-deficient mice to endotoxin. Immunity (1999) 11(1):115-22. doi: 10.1016/S1074-7613(00)80086-2

45. Yamamoto M, Sato S, Hemmi H, Hoshino K, Kaisho T, Sanjo H, et al. Role of adaptor TRIF in the MyD88-independent toll-like receptor signaling pathway. Science (2003) 301(5633):640-3. doi: 10.1126/science.1087262

46. Fitzgerald KA, Palsson-McDermott EM, Bowie AG, Jefferies CA, Mansell AS, Brady G, et al. Mal (MyD88-adapter-like) is required for Toll-like receptor-4 signal transduction. Nature (2001) 413(6851):78-83. doi: $10.1038 / 35092578$

47. Horng T, Barton GM, Medzhitov R. TIRAP: an adapter molecule in the Toll signaling pathway. Nat Immunol (2001) 2(9):835-41. doi: 10.1038/ni0901835

48. Yamamoto M, Sato S, Hemmi H, Uematsu S, Hoshino K, Kaisho T, et al. TRAM is specifically involved in the Toll-like receptor 4-mediated MyD88independent signaling pathway. Nat Immunol (2003) 4(11):1144-50. doi: 10.1038/ni986

49. Medzhitov R, Preston-Hurlburt P, Kopp E, Stadlen A, Chen C, Ghosh S, et al. MyD88 is an adaptor protein in the hToll/IL-1 receptor family signaling pathways. Mol Cell (1998) 2(2):253-8. doi: 10.1016/S1097-2765 (00)80136-7

50. Wesche H, Henzel WJ, Shillinglaw W, Li S, Cao Z. MyD88: an adapter that recruits IRAK to the IL-1 receptor complex. Immunity (1997) 7(6):837-47. doi: 10.1016/S1074-7613(00)80402-1

51. Muzio M, Ni J, Feng P, Dixit VM. IRAK (Pelle) family member IRAK-2 and MyD88 as proximal mediators of IL-1 signaling. Science (1997) 278 (5343):1612-5. doi: 10.1126/science.278.5343.1612

52. Yamamoto M, Sato S, Hemmi H, Sanjo H, Uematsu S, Kaisho T, et al. Essential role for TIRAP in activation of the signalling cascade shared by TLR2 and TLR4. Nature (2002) 420(6913):324-9. doi: 10.1038/ nature 01182

53. Kagan JC, Medzhitov R. Phosphoinositide-mediated adaptor recruitment controls Toll-like receptor signaling. Cell (2006) 125(5):943-55. doi: 10.1016/j.cell.2006.03.047

54. Motshwene PG, Moncrieffe MC, Grossmann JG, Kao C, Ayaluru M, Sandercock AM, et al. An oligomeric signaling platform formed by the Toll-like receptor signal transducers MyD88 and IRAK-4. J Biol Chem (2009) 284(37):25404-11. doi: 10.1074/jbc.M109.022392

55. Kagan JC, Magupalli VG, Wu H. SMOCs: supramolecular organizing centres that control innate immunity. Nat Rev Immunol (2014) 14(12):821-6. doi: $10.1038 /$ nri3757

56. Li S, Strelow A, Fontana EJ, Wesche H. IRAK-4: a novel member of the IRAK family with the properties of an IRAK-kinase. Proc Natl Acad Sci USA (2002) 99(8):5567-72. doi: 10.1073/pnas.082100399

57. Suzuki N, Suzuki S, Duncan GS, Millar DG, Wada T, Mirtsos C, et al. Severe impairment of interleukin-1 and Toll-like receptor signalling in mice lacking IRAK-4. Nature (2002) 416(6882):750-6. doi: 10.1038/nature736

58. Muzio M, Natoli G, Saccani S, Levrero M, Mantovani A. The human toll signaling pathway: divergence of nuclear factor kappaB and JNK/SAPK activation upstream of tumor necrosis factor receptor- associated factor 6 (TRAF6). J Exp Med (1998) 187(12):2097-101. doi: 10.1084/jem.187.12.2097 
59. Cao Z, Xiong J, Takeuchi M, Kurama T, Goeddel DV. TRAF6 is a signal transducer for interleukin-1. Nature (1996) 383(6599):443-6. doi: 10.1038/ $383443 \mathrm{a} 0$

60. Ye H, Arron JR, Lamothe B, Cirilli M, Kobayashi T, Shevde NK, et al. Distinct molecular mechanism for initiating TRAF6 signalling. Nature (2002) 418(6896):443-7. doi: 10.1038/nature00888

61. Ninomiya-Tsuji J, Kishimoto K, Hiyama A, Inoue J, Cao Z, Matsumoto K. The kinase TAK1 can activate the NIK-I kappaB as well as the MAP kinase cascade in the IL-1 signalling pathway. Nature (1999) 398(6724):252-6. doi: $10.1038 / 18465$

62. Wang C, Deng L, Hong M, Akkaraju GR, Inoue J, Chen ZJ. TAK1 is a ubiquitin-dependent kinase of MKK and IKK. Nature (2001) 412 (6844):346-51. doi: 10.1038/35085597

63. Tan Y, Kagan JC. Innate Immune Signaling Organelles Display Natural and Programmable Signaling Flexibility. Cell (2019) 177(2):384-398 e11. doi: 10.1016/j.cell.2019.01.039

64. Everts B, Amiel E, Huang SC, Smith AM, Chang CH, Lam WY, et al. TLRdriven early glycolytic reprogramming via the kinases TBK1-IKKvarepsilon supports the anabolic demands of dendritic cell activation. Nat Immunol (2014) 15(4):323-32. doi: 10.1038/ni.2833

65. Kagan JC, Su T, Horng T, Chow A, Akira S, Medzhitov R. TRAM couples endocytosis of Toll-like receptor 4 to the induction of interferon-beta. Nat Immunol (2008) 9(4):361-8. doi: 10.1038/ni1569

66. Fitzgerald KA, Rowe DC, Barnes BJ, Caffrey DR, Visintin A, Latz E, et al. LPS-TLR4 signaling to IRF-3/7 and NF-kB involves the toll adapters TRAM and TRIF. J Exp Med (2003) 198(7):1043-55. doi: 10.1084/ jem. 20031023

67. Oganesyan G, Saha SK, Guo B, He JQ, Shahangian A, Zarnegar B, et al. Critical role of TRAF3 in the Toll-like receptor-dependent and -independent antiviral response. Nature (2006) 439(7073):208-11. doi: 10.1038/ nature 04374

68. Liu S, Cai X, Wu J, Cong Q, Chen X, Li T, et al. Phosphorylation of innate immune adaptor proteins MAVS, STING, and TRIF induces IRF3 activation. Science (2015) 347(6227):aaa2630. doi: 10.1126/science. aaa2630

69. Fitzgerald KA, McWhirter SM, Faia KL, Rowe DC, Latz E, Golenbock DT, et al. IKKe and TBK1 are essential components of the IRF3 signaling pathway. Nat Immunol (2003) 4(5):491-6. doi: 10.1038/ni921

70. Sharma S, tenOever BR, Grandvaux N, Zhou GP, Lin R, Hiscott J. Triggering the interferon antiviral response through an IKK-related pathway. Science (2003) 300(5622):1148-51. doi: 10.1126/science.1081315

71. Dinarello CA. Interleukin-1 in the pathogenesis and treatment of inflammatory diseases. Blood (2011) 117(14):3720-32. doi: 10.1182/blood2010-07-273417

72. Fantuzzi G, Dinarello CA. Interleukin-18 and interleukin-1 beta: two cytokine substrates for ICE (caspase-1). J Clin Immunol (1999) 19(1):1-11. doi: 10.1023/a:1020506300324

73. Martinon F, Burns K, Tschopp J. The inflammasome: a molecular platform triggering activation of inflammatory caspases and processing of proIL-beta. Mol Cell (2002) 10(2):417-26. doi: 10.1016/S1097-2765(02)00599-3

74. Agostini L, Martinon F, Burns K, McDermott MF, Hawkins PN, Tschopp J. NALP3 forms an IL-1beta-processing inflammasome with increased activity in Muckle-Wells autoinflammatory disorder. Immunity (2004) 20(3):31925. doi: 10.1016/S1074-7613(04)00046-9

75. Stehlik C, Lee SH, Dorfleutner A, Stassinopoulos A, Sagara J, Reed JC. Apoptosis-associated speck-like protein containing a caspase recruitment domain is a regulator of procaspase-1 activation. J Immunol (2003) 171 (11):6154-63. doi: 10.4049/jimmunol.171.11.6154

76. Bauernfeind FG, Horvath G, Stutz A, Alnemri ES, MacDonald K, Speert D, et al. Cutting edge: NF-kappaB activating pattern recognition and cytokine receptors license NLRP3 inflammasome activation by regulating NLRP3 expression. J Immunol (2009) 183(2):787-91. doi: 10.4049/jimmunol.0901363

77. Loppnow H, Brade H, Durrbaum I, Dinarello CA, Kusumoto S, Rietschel ET, et al. IL-1 induction-capacity of defined lipopolysaccharide partial structures. J Immunol (1989) 142(9):3229-38.

78. Liu X, Pichulik T, Wolz OO, Dang TM, Stutz A, Dillen C, et al. Human NACHT, LRR, and PYD domain-containing protein 3 (NLRP3) inflammasome activity is regulated by and potentially targetable through
Bruton tyrosine kinase. J Allergy Clin Immunol (2017) 140(4):1054-67.e10. doi: 10.1016/j.jaci.2017.01.017

79. Song N, Liu ZS, Xue W, Bai ZF, Wang QY, Dai J, et al. NLRP3 Phosphorylation Is an Essential Priming Event for Inflammasome Activation. Mol Cell (2017) 68185-197(1):e6. doi: 10.1016/j.molcel.2017.08.017

80. Song H, Liu B, Huai W, Yu Z, Wang W, Zhao J, et al. The E3 ubiquitin ligase TRIM31 attenuates NLRP3 inflammasome activation by promoting proteasomal degradation of NLRP3. Nat Commun (2016) 7:13727. doi: 10.1038/ncomms13727

81. Han S, Lear TB, Jerome JA, Rajbhandari S, Snavely CA, Gulick DL, et al. Lipopolysaccharide Primes the NALP3 Inflammasome by Inhibiting Its Ubiquitination and Degradation Mediated by the SCFFBXL2 E3 Ligase. J Biol Chem (2015) 290(29):18124-33. doi: 10.1074/jbc.M115.645549

82. Shi J, Zhao Y, Wang K, Shi X, Wang Y, Huang H, et al. Cleavage of GSDMD by inflammatory caspases determines pyroptotic cell death. Nature (2015) 526(7575):660-5. doi: 10.1038/nature15514

83. Liu X, Zhang Z, Ruan J, Pan Y, Magupalli VG, Wu H, et al. Inflammasomeactivated gasdermin $\mathrm{D}$ causes pyroptosis by forming membrane pores. Nature (2016) 535(7610):153-8. doi: 10.1038/nature18629

84. Broz P, Pelegrín P, Shao F. The gasdermins, a protein family executing cell death and inflammation. Nat Rev Immunol (2019) 20:143-57. doi: 10.1038/s41577-0190228-2

85. Latz E, Xiao TS, Stutz A. Activation and regulation of the inflammasomes. Nat Rev Immunol (2013) 13(6):397-411. doi: 10.1038/nri3452

86. Gaidt MM, Ebert TS, Chauhan D, Schmidt T, Schmid-Burgk JL, Rapino F, et al. Human Monocytes Engage an Alternative Inflammasome Pathway. Immunity (2016) 44(4):833-46. doi: 10.1016/j.immuni.2016.01.012

87. Lee BL, Stowe IB, Gupta A, Kornfeld OS, Roose-Girma M, Anderson K, et al. Caspase-11 auto-proteolysis is crucial for noncanonical inflammasome activation. J Exp Med (2018) 215(9):2279-88. doi: 10.1084/jem.20180589

88. Kajiwara Y, Schiff T, Voloudakis G, Gama Sosa MA, Elder G, Bozdagi O, et al. A critical role for human caspase-4 in endotoxin sensitivity. J Immunol (2014) 193(1):335-43. doi: 10.4049/jimmunol.1303424

89. Kayagaki N, Stowe IB, Lee BL, O’Rourke K, Anderson K, Warming S, et al. Caspase-11 cleaves gasdermin $\mathrm{D}$ for non-canonical inflammasome signalling. Nature (2015) 526(7575):666-71. doi: 10.1038/nature15541

90. Wang K, Sun Q, Zhong X, Zeng M, Zeng H, Shi X, et al. Structural Mechanism for GSDMD Targeting by Autoprocessed Caspases in Pyroptosis. Cell (2020) 180(5):941-55. doi: 10.1016/j.cell.2020.02.002

91. Ding J, Wang K, Liu W, She Y, Sun Q, Shi J, et al. Pore-forming activity and structural autoinhibition of the gasdermin family. Nature (2016) 535 (7610):111-6. doi: 10.1038/nature18590

92. Sborgi L, Rühl S, Mulvihill E, Pipercevic J, Heilig R, Stahlberg H, et al. GSDMD membrane pore formation constitutes the mechanism of pyroptotic cell death. EMBO (2016) 35(16):1766-78. doi: 10.15252/ embj.201694696

93. Aglietti RA, Estevez A, Gupta A, Ramirez MG, Liu PS, Kayagaki N, et al. GsdmD p30 elicited by caspase-11 during pyroptosis forms pores in membranes. Proc Nat Acad Sci USA (2016) 113(28):7858-63. doi: 10.1073/ pnas. 1607769113

94. Ruan J, Xia S, Liu X, Lieberman J, Wu H. Cryo-EM structure of the gasdermin A3 membrane pore. Nature (2018) 557(7703):62-7. doi: 10.1038/s41586-018-0058-6

95. Rühl S, Broz P. Caspase-11 activates a canonical NLRP3 inflammasome by promoting $\mathrm{K}^{+}$efflux. Eur J Immunol (2015) 45(10):2927-36. doi: 10.1002/ eji.201545772

96. Gurung P, Malireddi RKS, Anand PK, Demon D, Walle LV, Liu Z, et al. Toll or Interleukin-1 Receptor (TIR) Domain-containing Adaptor Inducing Interferon- $\beta$ (TRIF)-mediated Caspase-11 Protease Production Integrates Toll-like Receptor 4 (TLR4) Protein- and Nlrp3 Inflammasome-mediated Host Defense against Enteropathogens. J Biol Chem (2012) 287(41):3447483. doi: 10.1074/jbc.M112.401406

97. Finethy R, Luoma S, Orench-Rivera N, Feeley EM, Haldar AK, Yamamoto $\mathrm{M}$, et al. Inflammasome Activation by Bacterial Outer Membrane Vesicles Requires Guanylate Binding Proteins. mBio (2017) 8(5):e01188-17. doi: 10.1128/mBio.01188-17

98. Santos JC, Dick MS, Lagrange B, Degrandi D, Pfeffer K, Yamamoto M, et al. LPS targets host guanylate-binding proteins to the bacterial outer membrane 
for non-canonical inflammasome activation. EMBO (2018) 37(6):e98089. doi: 10.15252/embj.201798089

99. Man SM, Karki R, Sasai M, Place DE, Kesavardhana S, Temirov J, et al. IRGB10 Liberates Bacterial Ligands for Sensing by the AIM2 and Caspase11-NLRP3 Inflammasomes. Cell (2016) 167(2):382-96. doi: 10.1016/ j.cell.2016.09.012

100. Mandal P, Feng Y, Lyons JD, Berger SB, Otani S, DeLaney A, et al. Caspase-8 Collaborates with Caspase-11 to Drive Tissue Damage and Execution of Endotoxic Shock. Immunity (2018) 49(1):42-55.e6. doi: 10.1016/ j.immuni.2018.06.011

101. Rietschel ET, Kirikae T, Schade FU, Mamat U, Schmidt G, Loppnow H, et al. Bacterial endotoxin: molecular relationships of structure to activity and function. FASEB J (1994) 8(2):217-25. doi: 10.1096/fasebj.8.2.8119492

102. Seydel U, Schromm AB, Blunck R, Brandenburg K. Chemical structure, molecular conformation, and bioactivity of endotoxins. Chem Immunol (2000) 74:5-24. doi: $10.1159 / 000058754$

103. Holst O. Structure of the lipopolysaccharide core region. In: YA Knirel and MA Valvano, editors. Bacterial Lipopolysaccharides. Vienna, Austria: Springer (2011). pp. 21-39. doi: 10.1007/978-3-7091-0733-1_2

104. Knirel Y. Structure of O-Antigens. In: YA Knirel and MA Valvano, editors. Bacterial Lipopolysaccharides. Vienna, Austria: Springer (2011). pp. 41-115. doi: 10.1007/978-3-7091-0733-1_3

105. Kawai T, Akira S. The role of pattern-recognition receptors in innate immunity: update on Toll-like receptors. Nat Immunol (2010) 11(5):37384. doi: $10.1038 /$ ni. 1863

106. Kobayashi M, Saitoh S, Tanimura N, Takahashi K, Kawasaki K, Nishijima M, et al. Regulatory roles for MD-2 and TLR4 in ligand-induced receptor clustering. J Immunol (2006) 176(10):6211-8. doi: 10.4049/jimmunol. 176.10.6211

107. Raetz CRH, Reynolds CM, Trent MS, Bishop RE. Lipid A modification systems in Gram-negative bacteria. Annu Rev Biochem (2007) 76(1):295329. doi: 10.1146/annurev.biochem.76.010307.145803

108. Raetz CRH, Whitfield C. Lipopolysaccharide Endotoxins. Annu Rev Biochem (2002) 71:635-700. doi: 10.1146/annurev.biochem.71.110601.135414

109. Kumar H, Kawai T, Akira S. Toll-like receptors and innate immunity. Biochem Biophys Res Commun (2009) 388(4):621-5. doi: 10.1016/ j.bbrc.2009.08.062

110. Bryant CE, Symmons M, Gay NJ. Toll-like receptor signalling through macromolecular protein complexes. Mol Immunol (2015) 63(2):162-5. doi: 10.1016/j.molimm.2014.06.033

111. Latty SL, Sakai J, Hopkins L, Verstak B, Paramo T, Berglund NA, et al. Activation of Toll-like receptors nucleates assembly of the MyDDosome signaling hub. eLife (2018) 7:e31377. doi: 10.7554/eLife.31377

112. Ohto U, Fukase K, Miyake K, Satow Y. Crystal structures of human MD-2 and its complex with antiendotoxic lipid IVa. Science (2007) 316 (5831):1632-4. doi: 10.1126/science.1139111

113. Kim HM, Park BS, Kim J-I, Kim SE, Lee J, Oh SC, et al. Crystal structure of the TLR4-MD-2 complex with bound endotoxin antagonist Eritoran. Cell (2007) 130:906-17. doi: 10.1016/j.cell.2007.08.002

114. Garate JA, Stöckl J, del Carmen Fernández-Alonso M, Artner D, Haegman $\mathrm{M}$, Oostenbrink C, et al. Anti-endotoxic activity and structural basis for human MD-2.TLR4 antagonism of tetraacylated lipid A mimetics based on $\beta G l c N(1 \leftrightarrow 1) \alpha G l c N$ scaffold. Innate Immun (2015) 21(5):490-503. doi: $10.1177 / 1753425914550426$

115. Artner D, Oblak A, Ittig S, Garate JA, Horvat S, Arrieumerlou C, et al. Conformationally constrained Lipid A mimetics for exploration of structural basis of TLR4/MD-2 activation by lipopolysaccharide. ACS Chem Biol (2013) 8(11):2423-32. doi: 10.1021/cb4003199

116. Bunnell E, Lynn M, Habet K, Neumann A, Perdomo CA, Friedhoff LT, et al. blocks the endotoxin response in human volunteers with experimental endotoxemia. Crit Care Med (2000) 28(8):2713-20:E5531. doi: 10.1097/ 00003246-200008000-00005

117. Borio A, Holgado A, Garate JA, Beyaert R, Heine H, Zamyatina A. Disaccharide-Based Anionic Amphiphiles as Potent Inhibitors of Lipopolysaccharide-Induced Inflammation. ChemMedChem (2018) 13 (21):2317-31. doi: 10.1002/cmdc.201800505

118. Meng J, Gong M, Björkbacka H, Golenbock DT. Genome-wide expression profiling and mutagenesis studies reveal that lipopolysaccharide responsiveness appears to be absolutely dependent on TLR4 and MD-2 expression and is dependent upon intermolecular ionic interactions. J Immunol (2011) 187(7):3683-93. doi: 10.4049/jimmunol.1101397

119. Teghanemt A, Re F, Prohinar P, Widstrom R, Gioannini TL, Weiss JP. Novel roles in human MD-2 of Phenylalanines 121 and 126 and Tyrosine 131 in activation of Toll-like receptor 4 by endotoxin. J Biol Chem (2008) 283 (3):1257-66. doi: 10.1074/jbc.M705994200

120. Resman N, Vasl J, Oblak A, Pristovsek P, Gioannini TL, Weiss JP, et al. Essential roles of hydrophobic residues in both MD-2 and Toll-like receptor 4 in activation by endotoxin. J Biol Chem (2009) 284(22):15052-60. doi: 10.1074/jbc.M901429200

121. Walsh C, Gangloff M, Monie T, Smyth T, Wei B, McKinley TJ, et al. Elucidation of the MD-2/TLR4 interface required for signaling by lipid IVa. J Immunol (2008) 181(2):1245-54. doi: 10.4049/jimmunol.181.2.1245

122. Needham BD, Carroll SM, Giles DK, Georgiou G, Whiteley M, Trent MS. Modulating the innate immune response by combinatorial engineering of endotoxin. Proc Natl Acad Sci USA (2013) 110(4):1464-9. doi: 10.1073/ pnas. 1218080110

123. Makimura Y, Asai Y, Sugiyama A, Ogawa T. Chemical structure and immunobiological activity of lipid A from Serratia marcescens LPS. J Med Microbiol (2007) 56(11):1440-6. doi: 10.1099/jmm.0.47327-0

124. Shimazu R, Akashi S, Ogata H, Nagai Y, Fukudome K, Miyake K, et al. MD-2, a molecule that confers lipopolysaccharide responsiveness on Tolllike Receptor 4. J Exp Med (1999) 189(11):1777-82. doi: 10.1084/jem.189. 11.1777

125. Prohinar P, Re F, Widstrom R, Zhang D, Teghanemt A, Weiss JP, et al. Specific high affinity interactions of monomeric endotoxin-protein complexes with Toll-like receptor 4 ectodomain. J Biol Chem (2007) 282 (2):1010-7. doi: 10.1074/jbc.M609400200

126. Wright SD, Ramos RA, Tobias PS, Ulevitch RJ, Mathison JC. CD14, a receptor for complexes of lipopolysaccharide (LPS) and LPS binding protein. Science (1990) 249(4975):1431-3. doi: 10.1126/science.1698311

127. Miyake K. Roles for accessory molecules in microbial recognition by Toll-like receptors. Innate Immun (2006) 12(4):195-204. doi: 10.1177/ 09680519060120040101

128. Rajaiah R, Perkins DJ, Ireland DDC, Vogel SN. CD14 dependence of TLR4 endocytosis and TRIF signaling displays ligand specificity and is dissociable in endotoxin tolerance. Proc Nat Acad Sci USA (2015) 112(27):8391-6. doi: 10.1073/pnas.1424980112

129. Zanoni I, Ostuni R, Marek L, Barresi S, Barbalat R, Barton G, et al. CD14 controls the LPS-induced endocytosis of Toll-like Receptor 4. Cell (2011) 147 (4):868-80. doi: 10.1016/j.cell.2011.09.051

130. Kim JII, Lee CJ, Jin MS, Lee CH, Paik SG, Lee H, et al. Crystal structure of CD14 and its implications for lipopolysaccharide signaling. J Biol Chem (2005) 280(12):11347-51. doi: 10.1074/jbc.M414607200

131. Eckert J, Kim Y, Kim J, Gortler K, Oh DY, Sur S, et al. The crystal structure of lipopolysaccharide binding protein reveals the location of a frequent mutation that impairs innate immunity. Immunity (2013) 39(4):647-60. doi: 10.1016/j.immuni.2013.09.005

132. Kelley SL, Lukk T, Nair SK, Tapping RII. The crystal structure of human soluble CD14 reveals a bent solenoid with a hydrophobic aminoterminal pocket. J Immunol (2013) 190(3):1304-11. doi: 10.4049/jimmunol. 1202446

133. Knodler LA, Crowley SM, Sham HP, Yang H, Wrande M, Ma C, et al. Noncanonical Inflammasome Activation of Caspase-4/Caspase-11 Mediates Epithelial Defenses against Enteric Bacterial Pathogens. Cell Host Microbe (2014) 16(2):249-56. doi: 10.1016/j.chom.2014.07.002

134. Meunier E, Dick MS, Dreier RF, Schurmann N, Broz DK, Warming S, et al. Caspase-11 activation requires lysis of pathogen-containing vacuoles by IFNinduced GTPases. Nature (2014) 509(7500):366-70. doi: 10.1038/ nature 13157

135. Aachoui Y, Leaf IA, Hagar JA, Fontana MF, Campos CG, Zak DE, et al. Caspase-11 Protects Against Bacteria That Escape the Vacuole. Science (2013) 339(6122):975-8. doi: 10.1126/science.1230751

136. Deng $\mathrm{M}$, Tang Y, Li W, Wang X, Zhang R, Zhang X, et al. The Endotoxin Delivery Protein HMGB1 Mediates Caspase-11-Dependent Lethality in Sepsis. Immunity (2018) 49(4):740-53. doi: 10.1016/j.immuni. 2018.08.016 
137. Harris HE, Raucci A. Alarmin(g) news about danger: Workshop on Innate Danger Signals and HMGB1. EMBO Rep (2006) 7(8):774-8. doi: 10.1038/ sj.embor.7400759

138. Youn JH, Oh YJ, Kim ES, Choi JE, Shin J-S. High Mobility Group Box 1 Protein Binding to Lipopolysaccharide Facilitates Transfer of Lipopolysaccharide to CD14 and Enhances Lipopolysaccharide-Mediated TNF- $\alpha$ Production in Human Monocytes. J Immunol (2008) 180(7):506774. doi: 10.4049/jimmunol.180.7.5067

139. Yang H, Wang H, Ju Z, Ragab AA, Lundbäck P, Long W, et al. MD-2 is required for disulfide HMGB1-dependent TLR4 signaling. J Exp Med (2015) 212(1):5-14. doi: 10.1084/jem.20141318

140. Li W, Deng M, Loughran PA, Yang M, Lin M, Yang C, et al. LPS Induces Active HMGB1 Release From Hepatocytes Into Exosomes Through the Coordinated Activities of TLR4 and Caspase-11/GSDMD Signaling. Front Immunol (2020) 11(229):1-13. doi: 10.3389/ fimmu.2020.00229

141. Vanaja S, Russo A, Behl B, Banerjee I, Yankova M, Deshmukh S, et al. Bacterial Outer Membrane Vesicles Mediate Cytosolic Localization of LPS and Caspase-11 Activation. Cell (2016) 165(5):1106-19. doi: 10.1016/ j.cell.2016.04.015

142. Kaparakis-Liaskos M, Ferrero RL. Immune modulation by bacterial outer membrane vesicles. Nat Rev Immunol (2015) 15(6):375-87. doi: 10.1038/ nri3837

143. Jäger J, Keese S, Roessle M, Steinert M, Schromm AB. Fusion of Legionella pneumophila outer membrane vesicles with eukaryotic membrane systems is a mechanism to deliver pathogen factors to host cell membranes. Cell Microbiol (2015) 17(5):607-20. doi: 10.1111/cmi.12392

144. Chen DJ, Osterrieder N, Metzger SM, Buckles E, Doody AM, DeLisa MP, et al. Delivery of foreign antigens by engineered outer membrane vesicle vaccines. Proc Nat Acad Sci USA (2010) 107(7):3099-104. doi: 10.1073/ pnas. 0805532107

145. Bomberger JM, MacEachran DP, Coutermarsh BA, Ye S, O’Toole GA, Stanton BA. Long-Distance Delivery of Bacterial Virulence Factors by Pseudomonas aeruginosa Outer Membrane Vesicles. PloS Pathog (2009) 5 (4):e1000382. doi: 10.1371/journal.ppat.1000382

146. Kesty NC, Mason KM, Reedy M, Miller SE, Kuehn MJ. Enterotoxigenic Escherichia coli vesicles target toxin delivery into mammalian cells. EMBO (2004) 23(23):4538-49. doi: 10.1038/sj.emboj.7600471

147. O’Donoghue EJ, Krachler AM. Mechanisms of outer membrane vesicle entry into host cells. Cell Microbiol (2016) 18(11):1508-17. doi: 10.1111/ cmi. 12655

148. Santos JC, Broz P. Sensing of invading pathogens by GBPs: At the crossroads between cell-autonomous and innate immunity. J Leukoc Biol (2018) 104 (4):729-35. doi: 10.1002/JLB.4MR0118-038R

149. Piro AS, Hernandez D, Luoma S, Feeley EM, Finethy R, Yirga A, et al. Detection of Cytosolic Shigella flexneri via a C-Terminal Triple-Arginine Motif of GBP1 Inhibits Actin-Based Motility. mBio (2017) 8(6):e01979-17. doi: 10.1128/mBio.01979-17

150. Pilla DM, Hagar JA, Haldar AK, Mason AK, Degrandi D, Pfeffer K, et al. Guanylate binding proteins promote caspase-11-dependent pyroptosis in response to cytoplasmic LPS. Proc Nat Acad Sci USA (2014) 111(16):604651. doi: 10.1073/pnas.1321700111

151. Lagrange B, Benaoudia S, Wallet P, Magnotti F, Provost A, Michal F, et al. Human caspase-4 detects tetra-acylated LPS and cytosolic Francisella and functions differently from murine caspase-11. Nat Commun (2018) 9(1):242. doi: 10.1038/s41467-017-02682-y

152. Li P, Jiang $\mathrm{W}, \mathrm{Yu} \mathrm{Q}$, Liu $\mathrm{W}$, Zhou P, Li J, et al. Ubiquitination and degradation of GBPs by a Shigella effector to suppress host defence. Nature (2017) 551(7680):378-83. doi: 10.1038/nature24467

153. Zwack EE, Feeley EM, Burton AR, Hu B, Yamamoto M, Kanneganti T-D, et al. Guanylate Binding Proteins Regulate Inflammasome Activation in Response to Hyperinjected Yersinia Translocon Components. Infect Immun (2017) 85(10):e00778-16. doi: 10.1128/IAI.00778-16

154. Feeley EM, Pilla-Moffett DM, Zwack EE, Piro AS, Finethy R, Kolb JP, et al. Galectin-3 directs antimicrobial guanylate binding proteins to vacuoles furnished with bacterial secretion systems. Proc Nat Acad Sci USA (2017) 114(9):E1698-706. doi: 10.1073/pnas.1615771114
155. Zhao J, Raetz CRH. A two-component Kdo hydrolase in the inner membrane of Francisella novicida. Mol Microbiol (2010) 78(4):820-36. doi: 10.1111/ j.1365-2958.2010.07305.x

156. Wang X, Ribeiro AA, Guan Z, McGrath SC, Cotter RJ, Raetz CRH. Structure and biosynthesis of free Lipid A molecules that replace lipopolysaccharide in Francisella tularensis subsp. novicida. Biochemistry (2006) 45(48):14427-40. doi: 10.1021/bi061767s

157. Wandel MP, Kim B-H, Park E-S, Boyle KB, Nayak K, Lagrange B, et al. Guanylate-binding proteins convert cytosolic bacteria into caspase- 4 signaling platforms. Nat Immunol (2020) 21(8):880-91. doi: 10.1038/ s41590-020-0697-2

158. Santos JC, Boucher D, Schneider LK, Demarco B, Dilucca M, Shkarina K, et al. Human GBP1 binds LPS to initiate assembly of a caspase-4 activating platform on cytosolic bacteria. Nat Commun (2020) p:3276. [Online]. doi: 10.1038/s41467-020-16889-z

159. Fujimoto Y, Shimoyama A, Saeki A, Kitayama N, Kasamatsu C, Tsutsui H, et al. Innate immunomodulation by lipophilic termini of lipopolysaccharide, synthesis of lipid As from Porphyromonas gingivalis and other bacteria and their immunomodulative responses. Mol Biosyst (2013) 9(5):987-96. doi: $10.1039 / \mathrm{c} 3 \mathrm{mb} 25477 \mathrm{a}$

160. Rossi O, Pesce I, Giannelli C, Aprea S, Caboni M, Citiulo F, et al. Modulation of Endotoxicity of Shigella Generalized Modules for Membrane Antigens (GMMA) by Genetic Lipid A Modifications. J Biol Chem (2014) 289 (36):24922-35. doi: 10.1074/jbc.M114.566570

161. Casabuono AC, van der Ploeg CA, Rogé AD, Bruno SB, Couto AS. Characterization of lipid A profiles from Shigella flexneri variant $\mathrm{X}$ lipopolysaccharide. Rapid Commun Mass Spectr (2012) 26(17):2011-20. doi: $10.1002 / \mathrm{rcm} .6306$

162. d'Hauteville H, Khan S, Maskell DJ, Kussak A, Weintraub A, Mathison J, et al. Two $m s b B$ Genes Encoding Maximal Acylation of Lipid A Are Required for Invasive Shigella flexneri to Mediate Inflammatory Rupture and Destruction of the Intestinal Epithelium. J Immunol (2002) 168(10):524051. doi: 10.4049/jimmunol.168.10.5240

163. Rallabhandi P, Awomoyi A, Thomas KE, Phalipon A, Fujimoto Y, Fukase K, et al. Differential Activation of Human TLR4 by Escherichia coli and Shigella flexneri 2a Lipopolysaccharide: Combined Effects of Lipid A Acylation State and TLR4 Polymorphisms on Signaling. J Immunol (2008) 180(2):1139-47. doi: 10.4049/jimmunol.180.2.1139

164. Kobayashi T, Ogawa M, Sanada T, Mimuro H, Kim M, Ashida H, et al. The Shigella OspC3 Effector Inhibits Caspase-4, Antagonizes Inflammatory Cell Death, and Promotes Epithelial Infection. Cell Host Microbe (2013) 13 (5):570-83. doi: 10.1016/j.chom.2013.04.012

165. Rund S, Lindner B, Brade H, Holst O. Structural analysis of the lipopolysaccharide from Chlamydia trachomatis serotype L2. J Biol Chem (1999) 274(24):16819-24. doi: 10.1074/jbc.274.24.16819

166. Yang C, Briones M, Chiou J, Lei L, Patton MJ, Ma L, et al. Chlamydia trachomatis Lipopolysaccharide Evades the Canonical and Noncanonical Inflammatory Pathways To Subvert Innate Immunity. mBio (2019) 10(2): e00595-19. doi: 10.1128/mBio.00595-19

167. Heine H, Muller-Loennies S, Brade L, Lindner B, Brade H. Endotoxic activity and chemical structure of lipopolysaccharides from Chlamydia trachomatis serotypes E and L2 and Chlamydophila psittaci 6BC. FEBS (2003) 270 (3):440-50. doi: 10.1046/j.1432-1033.2003.03392.x

168. Heine $\mathrm{H}$, Gronow S, Zamyatina A, Kosma P, Brade H. Investigation on the agonistic and antagonistic biological activities of synthetic Chlamydia lipid A and its use in in vitro enzymatic assays. Innate Immun (2007) 13(2):126-32. doi: $10.1177 / 0968051907079122$

169. Tsutsumi-Ishii Y, Shimada K, Daida H, Toman R, Nagaoka I. Low potency of Chlamydophila LPS to activate human mononuclear cells due to its reduced affinities for CD14 and LPS-binding protein. Int Immunol (2008) 20(2):199208. doi: 10.1093/intimm/dxm129

170. Adanitsch F, Shi J, Shao F, Beyaert R, Heine H, Zamyatina A. Synthetic glycan-based TLR4 agonists targeting caspase-4/11 for the development of adjuvants and immunotherapeutics. Chem Sci (2018) 9(16):3957-63. doi: 10.1039/C7SC05323A

171. Seydel U, Oikawa M, Fukase K, Kusumoto S, Brandenburg K. Intrinsic conformation of lipid $\mathrm{A}$ is responsible for agonistic and antagonistic activity. 
Eur J Biochem (2000) 267(10):3032-9. doi: 10.1046/j.1432-1033. 2000.01326.x

172. Schromm AB, Brandenburg K, Loppnow H, Moran AP, Koch MHJ, Rietschel ET, et al. Biological activities of lipopolysaccharides are determined by the shape of their lipid A portion. FEBS J (2000) 267 (7):2008-13. doi: 10.1046/j.1432-1327.2000.01204.x

173. Wacker MA, Teghanemt A, Weiss JP, Barker JH. High-affinity caspase-4 binding to LPS presented as high molecular mass aggregates or in outer membrane vesicles. Innate Immun (2017) 23(4):336-44. doi: 10.1177/ 1753425917695446

174. Barker JH, Weiss JP. Detecting lipopolysaccharide in the cytosol of mammalian cells: Lessons from MD-2/TLR4. J Leukocyte Biol (2019) 1-6. doi: 10.1002/JLB.3MIR1118-434R

175. Weiss J, Barker J. Diverse pro-inflammatory endotoxin recognition systems of mammalian innate immunity [version 1, peer review: 2 approved]. F1000Research (2018) 7(F1000 Faculty Rev)(516):1-11. doi: 10.12688/ f1000research.13977.1

176. An J, Kim SH, Hwang D, Lee KE, Kim MJ, Yang EG, et al. Caspase-4 disaggregates lipopolysaccharide micelles via LPS-CARD interaction. Sci Rep (2019) 9(1):826. doi: 10.1038/s41598-018-36811-4

177. Lee H, Hsu FF, Turk J, Groisman EA. The PmrA-Regulated pmrC Gene Mediates Phosphoethanolamine Modification of Lipid A and Polymyxin Resistance in Salmonella enterica. J Bacteriol (2004) 186(13):4124-33. doi: 10.1128/JB.186.13.4124-4133.2004

178. Winfield MD, Latifi T, Groisman EA. Transcriptional regulation of the 4amino-4-deoxy-L-arabinose biosynthetic genes in Yersinia pestis. J Biol Chem (2005) 280(15):14765-72. doi: 10.1074/jbc.M413900200

179. Kalhorn TF, Kiavand A, Cohen IE, Nelson AK, Ernst RK. A sensitive liquid chromatography/mass spectrometrybased assay for quantitation of aminocontaining moieties in lipid A. Rapid Commun Mass Spect (2009) 23(3):43342. doi: $10.1002 / \mathrm{rcm} .3900$

180. Gunn JS, Ernst RK. The structure and function of Francisella lipopolysaccharide. Ann N Y Acad Sci (2007) 1105(1):202-18. doi: 10.1196/annals. 1409.006

181. Marr N, Tirsoaga A, Blanot D, Fernandez R, Caroff M. Glucosamine found as a substituent of both phosphate groups in Bordetellae lipid A backbones: role of a BvgAS-activated ArnT ortholog. J Bacteriol (2008) 190(12):4281-90. doi: 10.1128/JB.01875-07

182. Hollaus R, Ittig S, Hofinger A, Haegman M, Beyaert R, Kosma $P$, et al. Chemical synthesis of Burkholderia Lipid A modified with glycosyl phosphodiester-linked 4-amino-4-deoxy- $\beta$-L-arabinose and its immunomodulatory potential. Chem Eur J (2015) 21:4102-14. doi: 10.1002/chem. 201406058

183. Di Lorenzo F, Kubik Ł, Oblak A, Lorè NII, Cigana C, Lanzetta R, et al. Activation of Human Toll-like Receptor 4 (TLR4).Myeloid Differentiation Factor 2 (MD-2) by Hypoacylated Lipopolysaccharide from a Clinical Isolate of Burkholderia cenocepacia. J Biol Chem (2015) 290(35):21305-19. doi: 10.1074/jbc.M115.649087

184. Kim S-H, Jia W, Parreira VR, Bishop RE, Gyles CL. Phosphoethanolamine substitution in the lipid A of Escherichia coli O157:H7 and its association with PmrC. Microbiology (2006) 152(3):657-66. doi: 10.1099/mic.0.28692-0

185. Pallett MA, Crepin VF, Serafini N, Habibzay M, Kotik O, Sanchez-Garrido J, et al. Bacterial virulence factor inhibits caspase-4/11 activation in intestinal epithelial cells. Mucosal Immunol (2017) 10(3):602-12. doi: 10.1038/ mi.2016.77

186. Song T, Li K, Zhou W, Zhou J, Jin Y, Dai H, et al. A Type III Effector NleF from EHEC Inhibits Epithelial Inflammatory Cell Death by Targeting Caspase-4. BioMed Res Int (2017) 2017:4101745. doi: 10.1155/2017/4101745

187. Tirsoaga A, El Hamidi A, Perry MB, Caroff M, Novikov A. A rapid, small-scale procedure for the structural characterization of lipid A applied to Citrobacter and Bordetella strains: discovery of a new structural element. J Lipid Res (2007) 48 (11):2419-27. doi: 10.1194/jlr.M700193-JLR200

188. Khan MA, Ma C, Knodler LA, Valdez Y, Rosenberger CM, Deng W, et al. Toll-like receptor 4 contributes to colitis development but not to host defense during Citrobacter rodentium infection in mice. Infect Immun (2006) 74 (5):2522-36. doi: 10.1128/IAI.74.5.2522-2536.2006

189. Sinha A, Nyongesa S, Viau C, Gruenheid S, Veyrier FJ, Le Moual H. PmrC (EptA) and CptA Negatively Affect Outer Membrane Vesicle Production in
Citrobacter rodentium. J Bacteriol (2019) 201(7):e00454-18. doi: 10.1128/ JB.00454-18

190. Matsuura M, Takahashi H, Watanabe H, Saito S, Kawahara K. Immunomodulatory properties of Yersinia pestis lipopolysaccharides on human macrophages. Clin Vaccine Immunol (2009) 17(1):49-55. doi: 10.1128/CVI.00336-09

191. Montminy SW, Khan N, McGrath S, Walkowicz MJ, Sharp F, Conlon JE, et al. Virulence factors of Yersinia pestis are overcome by a strong lipopolysaccharide response. Nat Immunol (2006) 7(10):1066-73. doi: 10.1038/ni1386

192. Therisod H, Karibian D, Perry MB, Caroff M. Structural analysis of Yersinia pseudotuberculosis ATCC 29833 lipid A. Int J Mass Spec (2002) 219(3):54957. doi: 10.1016/S1387-3806(02)00706-6

193. Marceau M, Sebbane F, Ewann F, Collyn F, Lindner B, Campos MA, et al. The pmrF polymyxin-resistance operon of Yersinia pseudotuberculosis is upregulated by the PhoP-PhoQ two-component system but not by PmrAPmrB, and is not required for virulence. Microbiology (2004) 150(12):394757. doi: $10.1099 /$ mic. $0.27426-0$

194. Aoyagi KL, Brooks BD, Bearden SW, Montenieri JA, Gage KL, Fisher MA. LPS modification promotes maintenance of Yersinia pestis in fleas. Microbiology (2015) 161(Pt 3):628-38. doi: 10.1099/mic.0.000018

195. Sarhan J, Liu BC, Muendlein HII, Li P, Nilson R, Tang AY, et al. Caspase-8 induces cleavage of gasdermin D to elicit pyroptosis during Yersinia infection. Proc Nat Acad Sci USA (2018) 115(46):E10888-97. doi: 10.1073/ pnas. 1809548115

196. Orning P, Weng D, Starheim K, Ratner D, Best Z, Lee B, et al. Pathogen blockade of TAK1 triggers caspase-8-dependent cleavage of gasdermin D and cell death. Science (2018) 362(6418):1064-9. doi: 10.1126/ science.aau 2818

197. Hajjar AM, Ernst RK, Fortuno ES, Brasfield AS, Yam CS, Newlon LA, et al. Humanized TLR4/MD-2 Mice Reveal LPS Recognition Differentially Impacts Susceptibility to Yersinia pestis and Salmonella enterica. PloS Pathog (2012) 8(10):e1002963. doi: 10.1371/journal.ppat.1002963

198. Broz P, Ohlson MB, Monack DM. Innate immune response to Salmonella typhimurium, a model enteric pathogen. Gut Microb (2012) 3(2):62-70. doi: 10.4161/gmic.19141

199. Zähringer U, Knirel YA, Lindner B, Helbig JH, Sonesson A, Marre R, et al. The lipopolysaccharide of Legionella pneumophila serogroup 1 (strain Philadelphia 1): chemical structure and biological significance. Prog Clin Biol Res (1995) 392:113-39.

200. Sweet CR, Ribeiro AA, Raetz CRH. Oxidation and Transamination of the 3"Position of UDP-N-Acetylglucosamine by Enzymes from Acidithiobacillus ferrooxidans: Role In The Formation Of Lipid A Molecules With Four Amide-Linked Acyl Chains. J Biol Chem (2004) 279(24):25400-10. doi: 10.1074/jbc.M400596200

201. Neumeister B, Faigle M, Sommer M, Zähringer U, Stelter F, Menzel R, et al. Low Endotoxic Potential of Legionella pneumophila Lipopolysaccharide due to Failure of Interaction with the Monocyte Lipopolysaccharide Receptor CD14. Infect Immun (1998) 66(9):4151-7. doi: 10.1128/IAI.66.9.41514157.1998

202. Albers U, Tiaden A, Spirig T, Al Alam D, Goyert SM, Gangloff SC, et al. Expression of Legionella pneumophila paralogous lipid A biosynthesis genes under different growth conditions. Microbiology (2007) 153(11):3817-29. doi: 10.1099/mic.0.2007/009829-0

203. Case CL, Kohler LJ, Lima JB, Strowig T, de Zoete MR, Flavell RA, et al. Caspase-11 stimulates rapid flagellin-independent pyroptosis in response to Legionella pneumophila. Proc Nat Acad Sci USA (2013) 110(5):1851-6. doi: 10.1073/pnas. 1211521110

204. Matamouros S, Miller SI. S. Typhimurium strategies to resist killing by cationic antimicrobial peptides. Biochim Biophys Acta (BBA) - Biomembranes (2015) 1848 (11, Part B):3021-5. doi: 10.1016/j.bbamem.2015.01.013

205. Kong Q, Six DA, Liu Q, Gu L, Wang S, Alamuri P, et al. Phosphate groups of lipid A are essential for Salmonella enterica serovar Typhimurium virulence and affect innate and adaptive immunity. Infect Immun (2012) 80(9):321524. doi: 10.1128/IAI.00123-12

206. Zhou Z, Ribeiro AA, Lin S, Cotter RJ, Miller SII, Raetz CRH. Lipid A Modifications in Polymyxin-resistant Salmonella typhimurium. PMRAdependent 4-amino-4-deoxy-L-arabinose, and phosphoethanolamine 
incorporation. J Biol Chem (2001) 276(46):43111-21. doi: 10.1074/ jbc.M106960200

207. Kawasaki K, Ernst RK, Miller SII. Inhibition of Salmonella enterica Serovar Typhimurium Lipopolysaccharide Deacylation by Aminoarabinose Membrane Modification. J Bacteriol (2005) 187(7):2448-57. doi: 10.1128/ JB.187.7.2448-2457.2005

208. Tamayo R, Prouty AM, Gunn JS. Identification and functional analysis of Salmonella enterica serovar Typhimurium PmrA-regulated genes. FEMS Immunol Med Microbiol (2005) 43(2):249-58. doi: 10.1016/j. femsim.2004.08.007

209. Sanchez-Garrido J, Slater SL, Clements A, Shenoy AR, Frankel G. Vying for the control of inflammasomes: The cytosolic frontier of enteric bacterial pathogen-host interactions. Cell Microbiol (2020) 22(4):e13184. doi: $10.1111 / \mathrm{cmi} .13184$

210. Wang X, Ribeiro AA, Guan Z, Abraham SN, Raetz CRH. Attenuated virulence of a Francisella mutant lacking the lipid A 4'-phosphatase. Proc Natl Acad Sci USA (2007) 104(10):4136-41. doi: 10.1073/pnas.0611606104

211. Phillips NJ, Schilling B, McLendon MK, Apicella MA, Gibson BW. Novel modification of lipid A of Francisella tularensis. Infect Immun (2004) 72 (9):5340-8. doi: 10.1128/IAI.72.9.5340-5348.2004

212. Wang X, Ribeiro AA, Guan Z, Raetz CRH. Identification of Undecaprenyl Phosphate- $\alpha$-D-Galactosamine in Francisella novicida and Its Function in Lipid A Modification. Biochemistry (2009) 48(6):1162-72. doi: 10.1021/ bi802211k

213. Beasley AS, Cotter RJ, Vogel SN, Inzana TJ, Qureshi AA, Qureshi N. A variety of novel lipid A structures obtained from Francisella tularensis live vaccine strain. Innate Immun (2012) 18(2):268-78. doi: 10.1177/ 1753425911401054

214. Kanistanon D, Hajjar AM, Pelletier MR, Gallagher LA, Kalhorn T, Shaffer SA, et al. A Francisella Mutant in Lipid A Carbohydrate Modification Elicits Protective Immunity. PloS Pathog (2008) 4(2):e24. doi: 10.1371/ journal.ppat.0040024

215. Li Y, Powell DA, Shaffer SA, Rasko DA, Pelletier MR, Leszyk JD, et al. LPS remodeling is an evolved survival strategy for bacteria. Proc Natl Acad Sci USA (2012) 109(22):8716-21. doi: 10.1073/pnas.1202908109

216. Hajjar AM, Harvey MD, Shaffer SA, Goodlett DR, Sjostedt A, Edebro H, et al. Lack of In Vitro and In Vivo Recognition of Francisella tularensis Subspecies Lipopolysaccharide by Toll-Like Receptors. Infect Immun (2006) 74 (12):6730-8. doi: 10.1128/IAI.00934-06

217. Duenas AII, Aceves M, Orduna A, Diaz R, Sanchez Crespo M, GarciaRodriguez C. Francisella tularensis LPS induces the production of cytokines in human monocytes and signals via Toll-like receptor 4 with much lower potency than E. coli LPS. Int Immunol (2006) 18(5):785-95. doi: 10.1093/ intimm/dxl015

218. Barker JH, Weiss J, Apicella MA, Nauseef WM. Basis for the Failure of Francisella tularensis Lipopolysaccharide To Prime Human Polymorphonuclear Leukocytes. Infect Immun (2006) 74(6):3277-84. doi: 10.1128/IAI.02011-05

219. Weiss DS, Henry THOM, Monack DM. Francisella Tularensis: Activation of the Inflammasome. Annal New York Acad Sci (2007) 1105(1):219-37. doi: 10.1196/annals.1409.005

220. Broz P, Monack DM. Molecular mechanisms of inflammasome activation during microbial infections. Immunol Rev (2011) 243(1):174-90. doi: 10.1111/j.1600-065X.2011.01041.x

221. Man SM, Karki R, Malireddi RKS, Neale G, Vogel P, Yamamoto M, et al. The transcription factor IRF1 and guanylate-binding proteins target activation of the AIM2 inflammasome by Francisella infection. Nat Immunol (2015) 16 (5):467-75. doi: 10.1038/ni.3118

222. Meunier E, Wallet P, Dreier RF, Costanzo S, Anton L, Ruhl S, et al. Guanylate-binding proteins promote activation of the AIM2 inflammasome during infection with Francisella novicida. Nat Immunol (2015) 16(5):476-84. doi: 10.1038/ni.3119

223. Chen W, KuoLee R, Shen H, Busa M, Conlan JW. Toll-like receptor 4 (TLR4) plays a relatively minor role in murine defense against primary intradermal infection with Francisella tularensis LVS. Immunol Lett (2005) 97(1):151-4. doi: 10.1016/j.imlet.2004.10.001

224. Cole LE, Mann BJ, Shirey KA, Richard K, Yang Y, Gearhart PJ, et al. Role of TLR signaling in Francisella tularensis-LPS-induced, antibody-mediated protection against Francisella tularensis challenge. J Leukocyte Biol (2011) 90(4):787-97. doi: 10.1189/jlb.0111014

225. Barker JH, Kaufman JW, Zhang DS, Weiss JP. Metabolic labeling to characterize the overall composition of Francisella lipid A and LPS grown in broth and in human phagocytes. Innate Immun (2014) 20(1):88-103. doi: $10.1177 / 1753425913485308$

226. Chalabaev S, Kim TH, Ross R, Derian A, Kasper DL. 3-Deoxy-D-mannooctulosonic acid (Kdo) hydrolase identified in Francisella tularensis, Helicobacter pylori, and Legionella pneumophila. J Biol Chem (2010) 285 (45):34330-6. doi: 10.1074/jbc.M110.166314

227. Shaffer SA, Harvey MD, Goodlett DR, Ernst RK. Structural Heterogeneity and Environmentally Regulated Remodeling of Francisella tularensis subspecies novicida Lipid A Characterized by Tandem Mass Spectrometry. J Am Soc Mass Spec (2007) 18(6):1080-92. doi: 10.1016/ j.jasms.2007.03.008

228. Kanistanon D, Powell DA, Hajjar AM, Pelletier MR, Cohen IE, Way SS, et al. Role of Francisella Lipid A Phosphate Modification in Virulence and LongTerm Protective Immune Responses. Infect Immun (2012) 80(3):943-51. doi: 10.1128/IAI.06109-11

229. Norris MH, Somprasong N, Schweizer HP, Tuanyok A. Lipid A Remodeling Is a Pathoadaptive Mechanism That Impacts Lipopolysaccharide Recognition and Intracellular Survival of Burkholderia pseudomallei. Infect Immun (2018) 86(10):e00360-18. doi: 10.1128/IAI.00360-18

230. Novem V, Shui G, Wang D, Bendt AK, Sim SH, Liu Y, et al. Structural and Biological Diversity of Lipopolysaccharides from Burkholderia pseudomallei and Burkholderia thailandensis. Clin Vaccine Immunol (2009) 16(10):14208. doi: 10.1128/CVI.00472-08

231. Ngugi SA, Ventura VV, Qazi O, Harding SV, Kitto GB, Estes DM, et al. Lipopolysaccharide from Burkholderia thailandensis E264 provides protection in a murine model of melioidosis. Vaccine (2010) 28(47):75515. doi: 10.1016/j.vaccine.2010.08.058

232. Panta PR, Kumar S, Stafford CF, Billiot CE, Douglass MV, Herrera CM, et al. A DedA Family Membrane Protein Is Required for Burkholderia thailandensis Colistin Resistance. Front Microbiol (2019) 10:2532-2. doi: 10.3389/fmicb. 2019.02532

233. Silipo A, Molinaro A, Cescutti P, Bedini E, Rizzo R, Parrilli M, et al. Complete structural characterization of the lipid A fraction of a clinical strain of B. cepacia genomovar I lipopolysaccharide. Glycobiology (2005) 15 (5):561-70. doi: 10.1093/glycob/cwi029

234. De Soyza A, Silipo A, Lanzetta R, Govan JR, Molinaro A. Chemical and biological features of Burkholderia cepacia complex lipopolysaccharides. Innate Immun (2008) 14(3):127-44. doi: 10.1177/1753425908093984

235. Silipo A, Molinaro A, Ieranò T, De Soyza A, Sturiale L, Garozzo D, et al. The complete ctructure and pro-inflammatory activity of the lipooligosaccharide of the highly epidemic and virulent Gram-negative bacterium Burkholderia cenocepacia ET-12 (Strain J2315). Chem Eur J (2007) 13(12):3501-11. doi: 10.1002/chem.200601406

236. Lorenzo FD, Sturiale L, Palmigiano A, Fazio LL, Paciello I, Coutinho CP, et al. Chemistry and biology of the potent endotoxin from a Burkholderia dolos a clinical isolate from a cystic fibrosis patient. ChemBioChem (2013) 14 (9):1105-15. doi: 10.1002/cbic.201300062

237. Chantratita N, Tandhavanant S, Myers ND, Seal S, Arayawichanont A, Kliangsa-ad A, et al. Survey of Innate Immune Responses to Burkholderia pseudomallei in Human Blood Identifies a Central Role for Lipopolysaccharide. PloS One (2013) 8(11):e81617. doi: 10.1371/ journal.pone.0081617

238. Wang J, Sahoo M, Lantier L, Warawa J, Cordero H, Deobald K, et al. Caspase-11-dependent pyroptosis of lung epithelial cells protects from melioidosis while caspase-1 mediates macrophage pyroptosis and production of IL-18. PloS Pathog (2018) 14(5):e1007105. doi: 10.1371/ journal.ppat.1007105

239. Ceballos-Olvera I, Sahoo M, Miller MA, Barrio LD, Re F. Inflammasomedependent Pyroptosis and IL-18 Protect against Burkholderia pseudomallei Lung Infection while IL-1 $\beta$ Is Deleterious. PloS Pathog (2011) 7(12): e1002452. doi: 10.1371/journal.ppat.1002452

240. Aachoui Y, Kajiwara Y, Leaf IA, Mao D, Ting JPY, Coers J, et al. Canonical Inflammasomes Drive IFN- $\gamma$ to Prime Caspase-11 in Defense against a 
Cytosol-Invasive Bacterium. Cell host Microbe (2015) 18(3):320-32. doi: 10.1016/j.chom.2015.07.016

241. Krause K, Caution K, Badr A, Hamilton K, Saleh A, Patel K, et al. CASP4/ caspase-11 promotes autophagosome formation in response to bacterial infection. Autophagy (2018) 14(11):1928-42. doi: 10.1080/15548627.2018.1491494

242. Yang J, Zhao Y, Shao F. Non-canonical activation of inflammatory caspases by cytosolic LPS in innate immunity. Curr Opin Immunol (2015) 32:78-83. doi: 10.1016/j.coi.2015.01.007

243. Rathinam VAK, Zhao Y, Shao F. Innate immunity to intracellular LPS. Nat Immunol (2019) 20(5):527-33. doi: 10.1038/s41590-019-0368-3
Conflict of Interest: The authors declare that the research was conducted in the absence of any commercial or financial relationships that could be construed as a potential conflict of interest.

Copyright $\odot 2020$ Zamyatina and Heine. This is an open-access article distributed under the terms of the Creative Commons Attribution License (CC BY). The use, distribution or reproduction in other forums is permitted, provided the original author(s) and the copyright owner(s) are credited and that the original publication in this journal is cited, in accordance with accepted academic practice. No use, distribution or reproduction is permitted which does not comply with these terms. 